\title{
1 Ballistic impact response of an UHMWPE fiber reinforced laminate encasing an aluminum-alumina hybrid panel
}

3

\author{
M.R. O’Masta ${ }^{a, *}$, B.G. Compton ${ }^{\text {b }}$, E.A. Gamble ${ }^{\text {b }}$, F.W. Zok ${ }^{\text {b }}$, V.S. Deshpande ${ }^{c}$ and H.N.G. \\ Wadley $^{\mathrm{a}}$ \\ a Department of Material Science \& Engineering, School of Engineering and Applied Science, \\ University of Virginia, Charlottesville, VA 22904, USA \\ ${ }^{\mathrm{b}}$ Materials Department, University of California, Santa Barbara, CA 93106, USA \\ ${ }^{\mathrm{c}}$ Cambridge University Engineering Department, Trumpington Street, Cambridge CB2 1PZ, UK
}

\begin{abstract}
The impact response of an ultrahigh molecular weight polyethylene (UHMWPE) fiber reinforced polymer matrix composite laminate has been investigated. The laminate encapsulated an aluminum alloy sandwich panel whose corrugated core was filled with prismatic alumina inserts. The laminate encased hybrid core target could sustain ceramic prism base impacts by a spherical, $12.7 \mathrm{~mm}$ diameter steel projectile with velocities in excess of $2.7 \mathrm{~km} \mathrm{~s}^{-1}$. This was $150 \%$ higher than the ballistic limit of an equal areal density, similarly encapsulated aluminum plate target. By contrast, when the projectile impacted a hybrid core target at the apex of a ceramic prism insert, failure of the UHMWPE laminate on the rear face occurred at a lower impact velocity. High-speed imaging, three-dimensional digital image correlation and x-ray tomography measurements are used to show that upon impact the projectile and the ceramic inserts fragment. These fragments then load the UHMWPE laminate on the rear face with a


24 significantly reduced pressure compared to the impact pressure of the projectile on the front

25 surface of the target. The loading area on the inner surface of the rear laminate was highest for a

26 prism base impact and lowest for a prism apex impact. The inability to penetrate the rear

27 laminate of the base impacted samples is consistent with the recent identification of an impact

28 pressure controlled mechanism of progressive penetration in this class of laminate.

29

30 Keywords: ballistics; polymeric composites; sandwich panels; aluminum alloys; alumina

31

32

$33 *$ Corresponding author.

34 E-mail address: mro4h@virginia.edu (M.R. O’Masta).

35 


\section{Introduction}

Ultra high molecular weight polyethylene (UHMWPE) fiber is one of the highest specific strength materials commercially available today [1], and is used to make ropes, sails, tear and cut resistant fabrics and ballistic impact protection systems. For ballistic applications, 10-20 $\mu \mathrm{m}$ diameter fibers are combined with thermoplastic polymer matrices to form thin $(\sim 50 \mu \mathrm{m}$ thick $)$

41 unidirectional plies containing $\sim 85 \%$ by volume fibers. Four of these plies are typically

42 combined to form a cross-ply $\left[0^{\circ} / 90^{\circ}\right]_{2}$ tape. The tapes can be stacked and hot pressed to form 43 cross-ply $\left[0^{\circ} / 90^{\circ}\right]_{\mathrm{n}}$ laminates that are attached to the rear of an armor system $[2,3]$ or molded to 44 form a protective structure [4].

The transverse impact of such a laminated polymer composite plate by a projectile causes

46 it to deflect out of plane. In a well-designed application, the resulting in-plane membrane stresses

47 create retarding forces on the projectile, eventually bringing it to rest before (elastic) fiber

48 fracture occurs [5]. However, a variety of recent experiments have identified a weaker

49 mechanism of panel response that appears to govern the initial interaction of the projectile with

50 such a target [1,6-10]. A progressive mechanism of penetration is often observed during high

51 velocity impact of edge restrained panels [6,11-15], and it is especially evident when back

52 supported, or very thick panels, are impacted at zero obliquity [1,16-18]. In these cases, the

53 laminates are unable to deflect out of plane, and instead, an impact pressure dependent mode of

54 penetration occurs $[12,16,17]$.

Attwood et al. [19] recently conducted a series of quasi-static compression tests on

56 UHMWPE fiber reinforced composite laminates to investigate their compressive response. They

57 discovered the existence of an indirect tension mode of ply failure when cross-ply laminates

58 were compressed (the mechanism was absent in unidirectional composites). Tension in the fiber 3 
59 direction of each ply was shown to be activated by lateral expansion of the orthogonally oriented

60 plies above and below them; a consequence of the very large anisotropy of the Poisson

61 expansion parallel and transverse to the ply fiber direction. As a result, as $\left[0^{\circ} / 90^{\circ}\right]_{\mathrm{n}}$ laminates are

62 subjected to out of plane compression, the fibers become loaded in tension by a shear lag

63 mechanism. When the tensile stress in a ply reaches the ply tensile strength, unstable ply fracture

64 (with large load drops under constant displacement rate loading) occurs. This mode of failure has

65 been observed in a wide variety of commercial polymer fiber reinforced cross-ply laminates, and

66 the critical pressure for ply failure has been shown to be sensitive to the tensile strength of the

67 plies and to the presence of ply defects [20].

68 During an impact event, a region of compression develops in a laminate under the

69 projectile. The magnitude of this stress scales with impact velocity, as well as with the shape,

70 density and sound speed of the projectile and its angle of impact [21,22]. Karthikeyan and

71 Russell [23] have suggested that penetration is sensitive to this impact induced compressive

72 stress, which is consistent with penetration being controlled by the indirect tensile fracture of a

73 ply's fibers. The work done in failing the ply, thereby advancing the projectile a ply thickness, is

74 supplied by a reduction of the kinetic energy of the projectile, and so as penetration continues,

75 the projectile slows until the pressure it exerts on the laminate becomes insufficient to cause

76 further indirect tension failure. If the intact section of laminate is sufficiently thick, the projectile

77 is then brought to rest by out of plane panel displacement against the forces resisting membrane

78 stretching.

79 This two mechanism penetration model suggests that any method that reduces the contact

80 pressure applied to the laminate by a projectile should delay the onset of fiber failure to higher

81 impact velocities. Data compiled for several fiber reinforced laminate systems does indeed show 4 
82 that the ballistic limit increases with the ratio of the projectile impact area to projectile mass [24].

83 Karthikeyan et al. [25] also observed that when edge clamped UHWMPE fiber reinforced

84 Dyneema ${ }^{\circledR}$ HB26 cross-ply laminates were impacted by large cross sectional area (but low

85 density) metal foam projectiles, the indirect tension mechanism could be suppressed, and the

86 impact energies sustained by the laminate were much greater than those for a localized impact by

87 a solid projectile of similar mass [6,25]. In the metal foam impact experiments, the location of

88 failure was also observed to move from the impact site (for solid projectiles) to the grips, and

89 novel gripping strategies that allowed pull-in of the laminate substantially improved the failure

90 impulse threshold.

91 O'Masta et al. [1] have recently impacted bi-material targets consisting of an aluminum

92 alloy plate wrapped in a (Dyneema ${ }^{\circledR}$ grade HB26) UHMWPE fiber reinforced laminate with a

93 spherical projectile, Fig. 1(a). The aluminum plate thickness was chosen to allow tests at the

94 shatter gap threshold for the projectile/alloy combination [26], while the Dyneema ${ }^{\circledR}$ wrapping

95 strategy was used to avoid grip region laminate failure modes. Impact velocity dependent

96 fragmentation of the projectile within the aluminum plate allowed the cross sectional area of the

97 debris exiting the aluminum plate (and therefore loading the inside of the rear laminate) to be

98 systematically varied. This enabled the cross sectional area of the laminate loading to be varied

99 by about a factor of two, and revealed that the penetration resistance of the laminate was

100 significantly increased as the loading area increased, Fig. 1(b) and (c). The study also led to the

101 discovery that out of plane bulging of the aluminum plate, prior to its perforation by the

102 projectile within, caused the rear laminate to be accelerated away from the alloy plate back face

103 before impact by the projectile debris, Fig. 1(a). This decreased the velocity difference between 
104 the laminate and the projectile, and allowed the laminate to sustain even higher velocity impacts

105 in comparison to cases where the rear laminate was stationary upon impact.

106 Several studies of the impact of hybrid sandwich panel structures whose cores contained

107 both hard ceramic, and ductile metallic materials have revealed interesting opportunities to tune

108 the impact debris spatial distribution, and potentially applying substantial acceleration to the rear

109 face of the structure during an impact event [27-31]. In a recent study of a model aluminum

110 sandwich panel, aluminum corrugations were filled with prismatic, triangular cross section

111 alumina inserts, and impacted above either a prism base or a prism apex, Fig. 2 [30]. The rear

112 aluminum face sheet was observed to suffer a large out of plane deflection prior to projectile and

113 target debris ejection. The width of deflected region and debris plume were found to be

114 controlled by the impact location on the front face of the target, and the base width of the

115 corrugated cells, $\mathrm{L}_{\mathrm{c}}$. Impacts above the base of a prism resulted in debris clouds whose width

116 was $\sim 2 \mathrm{~L}_{c}$, or four times that of an impacting projectile whose diameter was about $0.5 \mathrm{~L}_{c}$, Fig.

117 2(a). However impacts above a prism apex (a corrugation node), Fig. 2(b), resulted in an out of

118 plane deflection width of $\sim \mathrm{L}_{\mathrm{c}}$, and with a much increased debris exit velocity.

119 Repeating such an experiment with a hybrid core test structure encased in a cross-ply

120 UHMWPE fiber reinforced laminate would allow a further assessment of the consequences of

121 changing the rear laminate contact pressure. It will be shown that methods that reduce the contact

122 pressure, and therefore suppress failure by the indirect tension mechanism, substantially increase

123 the penetration resistance of the laminate.

124

125 2. Materials and Sample Fabrication 
We probe the effect of encasing hybrid Al/ceramic targets in Dyneema ${ }^{\circledR}$ using two types

127 of target designs: (i) an encased hybrid target as shown in Fig. 3(a) and (b) and (ii) the encased

128 target with the rear face cut out as shown in Fig. 3(c). The samples were fabricated using the

129 same 5.9 mm thick Dyneema ${ }^{\circledR}$ (DSM; Heerlen, The Netherlands) HB26 fiber-reinforced

130 laminate used in the O'Masta et al. [1] study with solid aluminum plates. The HB26 encased a

131 slightly modified version of the same hybrid core sandwich panel studied by Wadley et al. [30].

132 In the original Wadley et al. study, the 6061-T6 aluminum alloy sandwich panel had a triangular

133 corrugated core with $3.2 \mathrm{~mm}$ thick webs inclined at an angle of $60^{\circ}$ to two, $5.2 \mathrm{~mm}$ thick face

134 sheets, Fig. 2. In the present study, the thickness of the face sheet on the impact side of the

135 corrugated panel was reduced to $1.0 \mathrm{~mm}$, Fig. 4(a). With this modification, a hybrid core panel

136 with a $5.9 \mathrm{~mm}$ thick Dyneema ${ }^{\circledR} \mathrm{HB} 26$ laminate encasement had a mass per unit area of $\rho_{\mathrm{a}}=97$

$137 \mathrm{~kg} \mathrm{~m}^{-2}$; the same as the original (non-encased) hybrid panel, Fig. 2, and the encased aluminum 138 plate target, Fig. 1.

The model targets were assembled by filling the empty cells of the sandwich panel with

140 CoorsTek (Golden, CO) grade AD-995 triangular prisms that had been coated in Lord (Cary,

141 NC) grade 305 epoxy adhesive, Fig. 4(b). This ceramic has a hardness of $14.1 \mathrm{GPa}$, an elastic

142 modulus of $370 \mathrm{GPa}$ and a fracture toughness of $4-5 \mathrm{MN} \mathrm{m}^{-3 / 2}$. The panels were encased in

143 Dyneema $^{\circledR}$ grade HB26 cross-ply laminate. The HB26 laminate was fabricated from $67 \mu \mathrm{m}$ thick

144 unidirectional plies made from a polyurethane matrix and 83 vol.\% Dyneema ${ }^{\circledR}$ SK76 fiber whose

145 properties have been documented elsewhere, $[1,19,25,32]$. Two strips of $\left[0^{\circ} / 90^{\circ}\right]_{2} \mathrm{HB} 26$ pre-

146 preg tape were alternatively wrapped around the hybrid core panel followed by laminate

147 consolidation at an elevated temperature and pressure, Fig. 4(c-d). The lay-up of the laminate on

148 both $136 \mathrm{~mm} \times 132 \mathrm{~mm}$ faces was $\left[\left(90^{\circ} / 0^{\circ}\right)_{2} /\left(0^{\circ} / 90^{\circ}\right)_{2}\right]_{11}$ with a thickness of $5.9 \mathrm{~mm}$. This was 
149 twice the thickness of the four $\left[\left(0^{\circ} / 90^{\circ}\right)\right]_{22}$ sides and was identical to that used for the encased

150 aluminum targets [1]. The length of pre-preg strips was $\sim 5 \mathrm{~cm}$ longer than calculated for a

151 perfectly tight wrap. The excess (but densified) Dyneema ${ }^{\circledR}$ accumulated around the periphery of

152 the top (subsequently impacted) surface of the panels. The final dimensions of the encased

153 hybrid target are given in Fig. 3. Fig 3(a) also identifies reference planes, while Fig. 3(c) defines

154 sample external dimensions and a coordinate system used later.

155 To observe the hybrid sandwich panel's back face deflection, and the debris plume

156 incident upon the inside surface of the rear Dyneema ${ }^{\circledR}$ laminate during an impact event, a central

$157100 \mathrm{~mm} \times 100 \mathrm{~mm}$ square region of Dyneema ${ }^{\circledR}$ was removed using a rotary cutting tool. A

158 speckle pattern was applied to the aluminum surface to enable measurement of the surface

159 displacement of the back surface with a three-dimensional digital image correlation (DIC)

160 system. The exposed aluminum surface was first spray painted white, followed by the

161 application of a stochastic pattern of $1-3 \mathrm{~mm}$ diameter black dots that covered approximately

$16250 \%$ of the aluminum surface area.

\section{3. Impact Tests and Characterization}

The same spherical projectile (CCR Products LLC; West Hartford, CT) used in the earlier

166 studies of the encased aluminum plate and the bare hybrid core panel $[1,30]$ was used here. It had

167 a mass of $8.4 \mathrm{~g}$, was $12.7 \mathrm{~mm}$ in diameter, and was fabricated from 52100 chrome-steel. Its

168 measured hardness and compressive strength were 7.6 and 3.4 GPa, respectively. Each target

169 was edge clamped, and oriented for $0^{\circ}$ obliquity impact either at the mid-span of the $22 \mathrm{~mm}$ wide

170 base of the center ceramic prism, Fig. 5, or on the apex of one of the adjacent ceramic prisms.

171 The impact tests on the fully encased hybrid target were performed with a light-gas gun capable 
172 of launch velocities up to $3.5 \mathrm{~km} \mathrm{~s}^{-1}$ located at the University of California, Santa Barbara [31].

173 The impact velocity, Vi, was measured to within $\pm 0.4 \%$ using the time-of-flight recorded

174 between a pair of laser-gates. A model v.7.3 Phantom (Vision Research Inc.; Wayne, NJ) high-

175 speed video camera was oriented normal to the YZ plane, and recorded a backlit profile view of

176 the rear of the sample. The camera recordings used an exposure time of $1 \mu$ s and an inter-frame

177 interval of $19.5 \mu \mathrm{s}$. After impact, the samples were visually inspected for external damage. Some

178 samples were also examined by x-ray computed tomography (XCT) at Carl Zeiss Imaging

179 (Brighton, MI). All of the samples were then sectioned by water-jet cutting along the transverse

180 plane that intersected the impact sites.

The ballistic impacts of the rear face cutout targets were performed at Chesapeake

182 Testing (Belcamp, MD) where the more open geometry enabled 3D-DIC measurements to be

183 recorded. The impact velocities achievable with this powder gun were limited to $\mathrm{Vi}<2.3 \mathrm{~km} \mathrm{~s}^{-1}$

184 and were measured using paper break-screens. The Z-component of the residual velocity, $\mathrm{Vr}$, of

185 the leading edge of the debris released from perforated samples was calculated from video

186 images obtained with a model v.1610 Phantom high-speed camera oriented normal to the YZ

187 plane. The recordings used an exposure time of $0.76 \mu$ s and an inter-frame interval of $10 \mu \mathrm{s}$. A

188 pair of model Fastcam SA-X2 Photron (San Diego, CA) high-speed cameras were positioned in a 189 stereo configuration $\left(\alpha=17.5^{\circ}\right)$ behind the sample to record the deflection of the speckle pattern 190 coated rear aluminum surface, Fig. 6. Each black dot filled approximately 6 pixels of a camera’s

191 field of view. The cameras were positioned to the side of the Z-axis to avoid damage from debris 192 impact, and were synchronized to capture images at $6.67 \mu$ s intervals with an exposure time of 1 $193 \mu \mathrm{s}$. 
The DIC images were analyzed using the Aramis v.6.3 (GOM mbH; Braunschweig,

195 Germany) 3D image correlation software. This first divided one of the images from the stereo

196 pair into interrogation areas (facets). Each facet was uniquely defined by the speckle pattern

197 encompassed within its 15 pixel x 15 pixel area, and each linear raster of facets was spaced 5

198 pixels $(\sim 1.8 \mathrm{~mm})$ apart. A calibration, using images taken of a NIST-traceable calibration panel

199 (GOM mbH), was used to identify each facet in the second image pair and convert the facet

200 location into the laboratory frame (X, Y, Z) coordinate system. The locations of each facet were

201 recorded for each image pair for the sequence of video images, and the software then calculated

202 the full-field displacements and velocities over the speckled surface as functions of time.

203 Additional details can be found in references [33-35].

204

205 4. Results

206 4.1. Encased hybrid targets - ceramic prism base impacts

207 The majority of the fully encased targets were impacted at a prism base, mid-way along

208 the prism at impact velocities between 0.84 and $2.70 \mathrm{~km} \mathrm{~s}^{-1}$, while one sample was impacted on a

209 prism apex at a velocity of $2.5 \mathrm{~km} \mathrm{~s}^{-1}$. Table 1 summarizes the impact and residual (exit)

210 velocities for these experiments. The projectiles that impacted a prism base were arrested within

211 the samples without ejection of debris, while the impact on a prism apex resulted in full

212 perforation with a debris exit velocity of $0.2 \mathrm{~km} \mathrm{~s}^{-1}$. Table 2 summarizes the ballistic limits

213 measured previously for the encased aluminum and the hybrid core reference targets of identical

214 aerial density [1,30]. It is evident that the ballistic limit of the encased hybrid target tested here

215 was near double that of the reference targets.

216 
Table 1: Impact results for the encased hybrid and rear face cutout targets.

\begin{tabular}{l|lrrr}
\hline \multicolumn{1}{c}{ Target type } & \multicolumn{1}{c}{$\begin{array}{c}\text { Impact } \\
\text { location }\end{array}$} & $\begin{array}{c}\mathrm{Vi} \\
\left(\mathrm{km} \mathrm{s}^{-1}\right)\end{array}$ & $\begin{array}{c}\dot{\delta}_{\text {max }} \\
\left(\mathrm{km} \mathrm{s}^{-1}\right)\end{array}$ & $\begin{array}{c}\mathrm{Vr} \\
\left(\mathrm{km} \mathrm{s}^{-1}\right)\end{array}$ \\
\hline Encased hybrid & Base & 0.84 & $\mathrm{~N} / \mathrm{R}$ & 0 \\
& Base & 1.00 & $\mathrm{~N} / \mathrm{R}$ & 0 \\
& Base & 1.34 & $\mathrm{~N} / \mathrm{R}$ & 0 \\
& Base & 1.48 & $\mathrm{~N} / \mathrm{R}$ & 0 \\
& Base & 2.00 & $\mathrm{~N} / \mathrm{R}$ & 0 \\
& Base & 2.15 & $\mathrm{~N} / \mathrm{R}$ & 0 \\
& Base & 2.26 & $\mathrm{~N} / \mathrm{R}$ & 0 \\
& Base & 2.31 & $\mathrm{~N} / \mathrm{R}$ & 0 \\
& Node & 2.50 & $\mathrm{~N} / \mathrm{R}$ & 0.20 \\
& Base & 2.57 & $\mathrm{~N} / \mathrm{R}$ & 0 \\
& Base & 2.70 & $\mathrm{~N} / \mathrm{R}$ & 0 \\
\hline & Base & 1.71 & 0.32 & 0.43 \\
& Base & 1.84 & 0.34 & 0.50 \\
& Base & 1.92 & 0.35 & 0.49 \\
& Node & 2.00 & 0.40 & 0.82 \\
& Base & 2.17 & 0.45 & 0.80 \\
\hline
\end{tabular}

N/R: Not Recorded

219 Table 2: The ballistic limits of reference targets $\left(\rho_{\mathrm{a}}=97 \mathrm{~kg} \mathrm{~m}^{-2}\right)$ presented by the highest 220 impact velocity that failed to completely perforate the target and the lowest impact velocity that did.

\begin{tabular}{llcc}
\hline & Impact & \multicolumn{2}{c}{ Ballistic limit $\left(\mathrm{km} \mathrm{s}^{-1}\right)$} \\
\cline { 3 - 4 } Target type & location & Not perforated & Perforated \\
& & & \\
\hline Encased Al & Center & 1.37 & 1.41 \\
Hybrid & Base & 1.27 & 1.32 \\
Hybrid & Node & 0.98 & 1.15 \\
\hline
\end{tabular}


225 prism base are shown in Fig. 7. The front (upper) laminate was completely perforated by an

226 impact at $0.84 \mathrm{~km} \mathrm{~s}^{-1}$, Fig. 7(a). This was consistent with a previous measurement of $0.20 \mathrm{~km} \mathrm{~s}^{-1}$

227 for the ballistic limit of a $5.9 \mathrm{~mm}$ thick HB26 laminate supported on a foundation and impacted

228 by the same projectile, Table 3 [1]. The projectile then perforated the $1 \mathrm{~mm}$ thick front face sheet

229 and was arrested within the impacted ceramic prism, which suffered substantial comminution.

230 The hole seen in the impacted cell resulted from reverse flow of the comminuted ceramic and

231 projectile fragments through the entry hole during impact together with the loss of the remaining

232 fragments during cross-sectioning. Some microcracking of the two prisms on either side of the

233 impact can also be seen in Fig. 7(a). It is interesting to note that the Dyneema ${ }^{\circledR}$ entry hole had

234 partially closed after impact. The target suffered no measureable permanent back face deflection. (complete laminate failure) of $\sim 5.9 \mathrm{~mm}$ thick HB26 laminates when impacted by a $12.7 \mathrm{~mm}$ diameter steel sphere.

\begin{tabular}{llcc}
\hline & & \multicolumn{2}{c}{ Velocity $\left(\mathrm{km} \mathrm{s}^{-1}\right)$} \\
\cline { 3 - 4 } Target type & Support condition & Penetration & Perforation \\
\hline Encased aluminum [1] & Rear supported & $<0.11$ & 0.20 \\
Encased aluminum [1] & $\begin{array}{l}\text { Edge clamped }+ \\
\text { pre-acceleration }\end{array}$ & 0.24 & 0.60 \\
& Edge clamped & 0.24 & 0.45 \\
\hline
\end{tabular}

The effect of increasing the impact velocity can be seen in Fig. 7(b) and (c). The impact

241 at $1.37 \mathrm{~km} \mathrm{~s}^{-1}$ displaced a wide section of the rear face sheet in the Z-direction; sufficient to

242 cause fracture of the webs of the aluminum corrugated core and the rear face sheet. This resulted

243 in substantial permanent deflection, but no penetration of the rear laminate. The length of the

244 displaced face sheet region was approximately $50 \mathrm{~mm}$, or $\sim 2 \mathrm{~L}_{\mathrm{c}}$, in the X-direction. XCT results

245 for this sample, Fig. 8(a), show that the length of the displaced face sheet region in the Y-(prism 
246 axis) direction was about $75 \mathrm{~mm}$. The position of the hinges about which face sheet deflection

247 occurred, coincided with the base of the cone shaped region of severely microcracked ceramic,

248 Fig. 7(b) and 8. For impacts with $\mathrm{Vi} \geq 1.48 \mathrm{~km} \mathrm{~s}^{-1}$, the rear face sheet was longitudinally torn

249 directly beneath the impact site and at the two adjacent nodes in the X-direction, Fig. 7(c). Fig. 7

250 also shows that the hole on the front face increased in width as more substantial reverse debris

251 flow eroded the sides of the entry hole.

252 The displacement of the rear aluminum face sheet caused a permanent displacement of

253 the rear Dyneema ${ }^{\circledR}$ laminate by a distance that increased with impact velocity, Fig. 7 and 8 . At

$254 \mathrm{Vi}=2.05 \mathrm{~km} \mathrm{~s}^{-1}$, rotation of the fractured rear face sheet cut four to six of the Dyneema ${ }^{\circledR}$ plies

255 and allowed the comminuted ceramic and fragmented projectile debris to impact the laminate.

256 However, this debris impact appears to have caused no additional failure of the rear laminate.

257 The large stretching displacement suffered by the rear laminate appears to have been

258 accommodated by pull-in of plies from the sides and front of the encasement. At the highest test

259 velocity $\left(2.7 \mathrm{~km} \mathrm{~s}^{-1}\right)$, portions of the laminate encasement at the sides of the sample began to fail,

260 Fig. 9(a). No local penetration of the laminate at the impact location was observed in any of the

261 prism base impact experiments.

262 A high-speed image sequence showing the back face profile of the encased hybrid target 263 impacted at $2.70 \mathrm{~km} \mathrm{~s}^{-1}$ is shown in Fig. 10. At $\mathrm{t}=15 \mu \mathrm{s}^{*}$, the laminate on the rear of the sample

264 had been displaced $12 \mathrm{~mm}$ in the Z-direction and formed a $58 \mathrm{~mm}$ wide bulge in the $\mathrm{Y}$-direction, 265 consistent with acceleration by a bulging rear aluminum face sheet. The initial out of plane (Z266 component) velocity was $0.5 \mathrm{~km} \mathrm{~s}^{-1}$, and the distance of the laminate's Z- component deflection

\footnotetext{
${ }^{*}$ Time $\mathrm{t}=0 \pm 4 \mu \mathrm{s}$ was the estimated time of the start of deflection.
} 
267 increased with time as the aluminum face sheet was fractured and released debris against the

268 laminate. The laminate deflection was accommodated by transverse hinges that propagated away

269 from the impact site with a Y-component velocity of $0.32 \pm 0.03 \mathrm{~km} \mathrm{~s}^{-1}$; identical to that

270 measured for encased aluminum samples. The finger-like protrusions visible at $t \geq 171 \mu \mathrm{s}$, were

271 delaminated X-oriented fibers that had failed at a side grip. The side edge of the outermost tape

272 strip is highlighted in the $\mathrm{t}=366 \mu$ s image. This edge feature was a result of the combined pull-

273 in and tensile rupture of laminate material, as previously shown in Fig. 9(a). The impact was

274 arrested within $600 \mu \mathrm{s}$, after a maximum out of plane deflection of $82 \mathrm{~mm}$.

275

276 4.2. Encased hybrid targets - ceramic prism apex impacts

277 A cross-sectional view of the encased hybrid core target impacted at the apex of a 278 ceramic prism at $\mathrm{Vi}=2.50 \mathrm{~km} \mathrm{~s}^{-1}$ is shown in Fig. 9(b). Like a base impact at this impact

279 velocity, the rear laminate transversely deflected, pulled material in from the sides and portions 280 failed in tension along the sides of the sample. However, in the apex impact case, the laminate 281 was perforated below the impact site leaving a $\sim 10 \mathrm{~mm}$ diameter hole, Fig. 9(c).

\subsection{Rear face cutout targets - ceramic prism base impacts}

The rear face cutout targets were impacted at a prism base at velocities of 1.71 to $2.29 \mathrm{~km}$

$285 \mathrm{~s}^{-1}$, Table 1. As with the encased hybrid targets, the projectile first perforated the front laminate 286 and the thin aluminum front face sheet followed by fragmentation against the base of the center 287 ceramic prism and activation of hybrid core failure mechanisms. For the $1.71 \mathrm{~km} \mathrm{~s}^{-1}$ impact, the 288 high-speed video image sequence from one of the oblique rear view cameras of the speckle 289 coated rear face sheet is shown in Fig. 11(a). A contour map of the out of plane (Z-component) 14 
290 velocity, $\dot{\delta}$, determined from DIC analysis is overlaid. At $\mathrm{t}=4 \mu \mathrm{s}$, a small bulge formed on the 291 rear face sheet. Longitudinal and transverse displacement profiles across the peak of the bulge 292 revealed it was longer in the longitudinal direction (Y-axis) than the transverse direction (X293 axis), Fig. 12(a) and (b). The dimensions of the bulge and its velocity increased with time, and a 294 Y-oriented tear in the face sheet ${ }^{\dagger}$ started to develop below the node of the centrally impacted cell 295 by $\mathrm{t}=24 \mu \mathrm{s}$ when the peak deflection reached about $6 \mathrm{~mm}$. Ejecta then exited from the tear, as 296 seen in the last frame of Fig. 11(a), and from the profile view of the impact in Fig. 11(b). The 297 plume of debris had a blunt front and was $\sim 44 \mathrm{~mm}$ wide in the Y-direction, which is consistent 298 with the dimension of the face sheet tear opening, Fig. 8 and 12(b), and the dynamic rear 299 laminate deflection profile, Fig. 10. At the fastest tested impact velocity, Vi $=2.29 \mathrm{~km} \mathrm{~s}^{-1}$, the 300 shape of the bulge along the longitudinal plane was similar to the lower impact velocity, but the 301 transverse profile was more localized, Fig. 12(c) and (d).

302 The DIC determined velocity at the most deflected location, $\dot{\delta}_{\text {peak }}$, is plotted in Fig. 13 as 303 a function of time for the two impact velocities. For the $1.71 \mathrm{~km} \mathrm{~s}^{-1}$ impact, the rear face sheet 304 accelerated to a maximum deflection rate $\dot{\delta}_{\max }=0.30 \mathrm{~km} \mathrm{~s}^{-1}$ at t $=17 \mu \mathrm{s}$. The $2.29 \mathrm{~km} \mathrm{~s}^{-1}$ impact 305 required a similar time to reach $\dot{\delta}_{\max }=0.45 \mathrm{~km} \mathrm{~s}^{-1}$. In general, $\dot{\delta}_{\max }$ monotonically increased 306 with impact velocity, Fig. 14, as did the terminal debris velocity (increasing from $\mathrm{Vr}=0.43 \mathrm{~km}$ $307 \mathrm{~s}^{-1}$ to $\left.0.62 \mathrm{~km} \mathrm{~s}^{-1}\right)$. While the values of $\mathrm{Vr}$ were near or above the perforation limit of the 308 laminate when impacted by an intact sphere, Table 3, the difference between $\dot{\delta}_{\max }$ and the faster 309 traveling debris, $\mathrm{Vr}$, was only 0.1 to $0.2 \mathrm{~km} \mathrm{~s}^{-1}$ across the test velocity range. A laminate attached

\footnotetext{
† DIC facets were not resolved along a tear since the fracture surface changed the identifying "pattern" within a facet's interrogation area.
} 
310 to the rear face sheet would therefore have been pre-accelerated by the motion of the large area

311 face sheet bulge, which would have reduced the debris impact velocity in the laminate frame of

312 reference.

313

\section{4.4. Rear face cutout targets - ceramic prism apex impacts}

315 A high-speed video image sequence of the speckle coated rear face sheet of a rear face

316 cutout target impact at a prism apex is shown in Fig. 15. Two bulges were initially observed at $\mathrm{t}$

$317=4 \mu \mathrm{s}$. The bulges occurred at the two corrugated web - face sheet nodes on either side of the

318 base of the apex impacted ceramic prism. The peaks merged into one bulge with a $20 \mathrm{~mm}$ wide

319 transverse front by $\mathrm{t}=10 \mu \mathrm{s}$, Fig. 16. Two $\mathrm{Y}$-oriented cracks formed by $\mathrm{t}=30 \mu \mathrm{s}$ and allowed

320 the portion of the rear face sheet under the impacted prism to be subsequently torn away,

321 facilitating release of the debris, Fig. 15. The out of plane velocity at the location of peak

322 deflection, $\dot{\delta}_{\text {peak }}$, was shown as a function of time in Fig. 13. The response was similar to those

323 of the base impacts. However the residual velocity, $\mathrm{Vr}=0.8 \mathrm{~km} \mathrm{~s}^{-1}$, of the debris in this case was

324 substantially higher than the residual velocity for a prism base impact and about $0.4 \mathrm{~km} \mathrm{~s}^{-1}$ faster

325 than the back face sheet maximum velocity prior to debris emission, Fig. 14. Thus the rear face

326 sheet of a sample impacted at a prism apex bulged at a similar out of plane velocity to a prism

327 base impact; but the released debris after face sheet failure travelled at more than twice the speed 328 as that for a prism base impact at similar incident velocity.

330 5. Discussion

By impacting a model alumina filled hybrid sandwich panel at either a ceramic prism

332 base or apex, it has been possible to modify the dynamic loading of a rear, $5.9 \mathrm{~mm}$ thick 16 
333 Dyneema ${ }^{\circledR}$ laminate. A previous study [1] has shown that the front (back supported) Dyneema ${ }^{\circledR}$

334 laminate of an encased aluminum plate impacted by the same, $12.7 \mathrm{~mm}$ diameter spherical steel

335 projectile, was perforated once the impact velocity exceeded $0.2 \mathrm{~km} \mathrm{~s}^{-1}$, Table 3 . We therefore

336 assume that the projectile velocity that penetrated the front laminate and struck the $1 \mathrm{~mm}$ thick

337 front aluminum face sheet did so with an impact velocity reduced by $0.2 \mathrm{~km} \mathrm{~s}^{-1}$. This velocity

338 was sufficient to perforate the aluminum face sheet and impact either the $22 \mathrm{~mm}$ wide base of the

339 center ceramic prism or the apex of one of the adjacent prisms. The high hardness (14.1 GPa)

340 and elastic stiffness (370 GPa) of the alumina resulted in sufficiently high contact pressures

341 during impact to cause projectile fragmentation at the prism interface. The low fracture

342 toughness of the alumina (4-5 $\mathrm{MN} \mathrm{m}^{-3 / 2}$ ) resulted in the formation of a mescal zone of highly

343 comminuted and pulverized ceramic under the projectile impact site. Cone and radial cracks

344 readily form in alumina tiles [36], but these were disrupted here by the discontinuous nature of

345 the prisms and the ductile aluminum webs. Nevertheless, as the impact velocity increased, the

346 volume of damaged ceramic material increased. Since there was no ceramic disruption along the

347 axis of the prisms, distance of damaged ceramic was greater along the corrugation direction (Y-

348 axis) than transverse to it (X-axis).

349 The impulse applied to the rear Dyneema ${ }^{\circledR}$ laminate by the fragmented ceramic and

350 projectile debris plume depended upon the site of impact. Impacts at a prism base resulted in a 50

$351 \mathrm{~mm}$ wide square shaped region of the rear face sheet being displaced out of plane (Z-direction).

352 After exceeding a displacement of $10 \mathrm{~mm}$, debris was ejected from the fractured rear aluminum

353 face sheet as a more than $40 \mathrm{~mm}$ wide plume, with a velocity that increased from 0.43 to $0.62 \mathrm{~km}$

$354 \mathrm{~s}^{-1}$ as the target incident velocity increased from 1.7 to $2.3 \mathrm{~km} \mathrm{~s}^{-1}$, Fig. 14 . The greatly reduced

355 debris velocity in comparison to the projectile incident velocity is attributed to the large volume 17 
356 (mass) of fragmented ceramic (approximately three prism cross sections), Fig. 8, over which the 357 projectile momentum was distributed, and the effectiveness, at lower impact velocities, of the 358 front laminate at limiting reverse ejecta flow (and application of its reaction momentum).

359 However, it is still remarkable that impacts at velocities as high as $2.7 \mathrm{~km} \mathrm{~s}^{-1}$ failed to rupture the 360 rear Dyneema ${ }^{\circledR}$ laminate behind the location of debris impact. 17. The pressure applied by the debris was highest at the bottom (apex node) of the impacted cell

363 causing the node and face sheet to fail in tension at the face sheet/node interface, Fig 17(a). The 364 ductile aluminum face sheet then began to bend about plastic hinges that propagated to the left 365 and right until arrest at the two adjacent nodes. Fig. 7(b) and 17(a) show that this accelerated a 366 region of face sheet with a width given by $\sim 2 \mathrm{~L}_{\mathrm{c}}$ outwards reaching a maximum out of plane 367 velocity that increased with impact velocity, Fig. 14. This in turn accelerated the rear Dyneema ${ }^{\circledR}$ 368 laminate with a force that was distributed over a similarly large area. Fig. 13 shows that for the 369 target impacted at $2.3 \mathrm{~km} \mathrm{~s}^{-1}$ the rear face sheet required approximately $10 \mu \mathrm{s}$ to reach a velocity 370 of $0.45 \mathrm{~km} \mathrm{~s}^{-1}$. This was sufficient time for the $5.9 \mathrm{~mm}$ thick laminate (with a Z-direction 371 longitudinal wave speed of slightly more than $2 \mathrm{~km} \mathrm{~s}^{-1}$ [21] and transverse hinge speed of about $3720.3 \mathrm{~km} \mathrm{~s}^{-1}$ ) to transversely deflect, and maintain the impact pressure below the threshold needed 373 to induce indirect tension mode of progressive ply failure. At higher target impact velocities, the 374 faces of the fractured face sheet at the bottom apex node separated, and then released the debris 375 plume to impact the inside of the rear laminate over a region with a width given of $\sim 1.5 \mathrm{~L}_{\mathrm{c}}$, Fig 376 17(b). While the velocity of the debris over the test range could have been traveling in excess of

$3770.6 \mathrm{~km} \mathrm{~s}^{-1}$, the velocity difference between the debris and slower traveling aluminum face sheet 378 was less than $0.2 \mathrm{~km} \mathrm{~s}^{-1}$, Fig. 14. The Z-component motion of the face sheet provided a 18 
mechanism to reduce the velocity of the impacting debris in the laminate frame of reference.

380 This limited the debris impact pressure, and ensured that it did not exceed the (typically $1.5 \mathrm{GPa}$ )

381 pressure required to activate the indirect tension mode of failure.

382 This observation is consistent with the behavior of the encased aluminum target, where

383 an impact by the same spherical projectile caused the rear face of the aluminum plate to bulge

384 (with an area limited to $\sim 2 \mathrm{x}$ the projectile diameter) prior to plate perforation, Fig. 1(a). This

385 resulted in a small pre-acceleration of the rear $5.9 \mathrm{~mm}$ thick HB26 laminate which was then

386 impacted by an intact projectile that exited the rear of the aluminum plate with a velocity of 0.6

$387 \mathrm{~km} \mathrm{~s}^{-1}$ which exceeded the ballistic limit of a $5.9 \mathrm{~mm}$ thick, stationary, edge clamped Dyneema ${ }^{\circledR}$

388 laminate impacted by this projectile, Table 3 . The indirect tension activation pressure (a property

389 intrinsic to the laminate) remains the same in the pre-accelerated and stationary impact

390 situations; only the impact velocity (and hence contact pressure) applied to the laminate in the

391 pre-accelerated case was lower. Interestingly, impacts at a velocity of only $0.24 \mathrm{~km} \mathrm{~s}^{-1}$ are

392 sufficient to start progressive indirect tensile failure, Table 3 . The lack of any penetration in the

393 encased hybrid target can be understood by considering the pressure applied to the laminate by a

394 plume of debris particles scales as $\rho \mathrm{Vi}^{2}$, where $\rho$ is the plume density. The steel projectile is

395 many times more dense than that of the plume of aluminum, alumina and fragmented debris.

396 This, combined with the lower velocity of the debris plume and greater pre-acceleration applied

397 to the laminate, resulted in i) an increase in penetration initiation velocity of the rear laminate

398 from $0.2 \mathrm{~km} \mathrm{~s}^{-1}$ to more than $0.6 \mathrm{~km} \mathrm{~s}^{-1}$ in the laboratory frame of reference, and ii) an increase

399 in ballistic limit of the target from $1.4 \mathrm{~km} \mathrm{~s}^{-1}$ for the Dyneema ${ }^{\circledR}$ encased aluminum plate sample

400 to more than $2.7 \mathrm{~km} \mathrm{~s}^{-1}$ for the prism base impacted sample (of the same areal density). 
Debris penetration of the rear Dyneema ${ }^{\circledR}$ laminate after a prism apex impact can also be

402 rationalized by a similar analysis. The impact again displaced the rear aluminum face sheet

403 outward, at a velocity similar to that of a base prism impact, and therefore pre-accelerated the

404 rear Dyneema ${ }^{\circledR}$ laminate to a similar Z-direction velocity, Fig. 17(d). In an apex impact however,

405 the mass of comminuted ceramic was significantly less, Fig. 17(c), and the momentum

406 transferred to it by the projectile therefore resulted in a higher debris velocity [30]. For a target

407 impacted at $2 \mathrm{~km} \mathrm{~s}^{-1}$, the velocity difference between the debris and rear aluminum face sheet

408 was approximately $0.4 \mathrm{~km} \mathrm{~s}^{-1}$ for a ceramic prism node but only $0.1 \mathrm{~km} \mathrm{~s}^{-1}$ for a base impact,

409 Fig. 14. It is expected that the debris impact velocity in the laminate frame of reference would

410 have continued to increase with target impact velocity, and the higher pressure that was applied

411 to the laminate resulted in perforation for the $2.5 \mathrm{~km} \mathrm{~s}^{-1}$ prism apex impact.

412 In cases where the debris plume that exited the rear of the aluminum sandwich panel was

413 captured by the rear Dyneema ${ }^{\circledR}$ laminate, its kinetic energy could be dissipated by membrane

414 stretching of the full thickness of the rear laminate. Pull-in from the side and front laminates, and

415 straightening of excess consolidated Dyneema ${ }^{\circledR}$ combined to a give larger Z-direction

416 displacement than would have been possible if a side supported rear face laminate (i.e. a typical

417 bolted spall shield) had been impacted, and this presumably enabled kinetic energy dissipation at

418 reduced membrane stress. While no back laminate failure was observed for any of the prism base

419 impacts, some tensile fracture at the sides of the samples impacted at the highest velocity was

420 observed. This was not unexpected since the number of fibers aligned with the tensile load at the

421 sides of the sample was only a half that of the back laminate. This mode of response, as well as

422 deflection behavior, is similar to that observed when beams of the same laminate were impacted

423 by low-density aluminum foam projectiles [25]. 
425 resistance of a laminate. Placement of a suitable material between the projectile and laminate can 426 allow temporal and spatial modification of the material that impacts a laminate at the rear of the

427 target. The use of the hybrid core sandwich panel here provided an effective means of activating 428 projectile defeat by controlling the area of debris impacting the laminate backing. The study has 429 not investigated the best hybrid sandwich structure design (e.g. face sheet thickness, web/face 430 sheet nodal strength, cell topology and cell size), or material properties (e.g. density, yield 431 strength, toughness and ductility), or the best ceramic type, dimensions, topology, etc. These 432 would need to be considered in relation to the impactor (density, size, shape, velocity and 433 obliquity of impact) and type of laminate backing. The study has shown that laminate selection 434 should address material indices that maximize both the usual membrane mode of action and the 435 indirect tension mode of failure. It is finally noted that the laminate encasement method utilized 436 here was of substantial benefit since it enabled the back, side and front portions of the laminate 437 to all contribute to membrane stretching, and eliminated stress concentrations at bolt hole 438 attachments that would be otherwise necessary.

\section{Conclusions}

441 The impact performance of an UHMWPE fiber reinforced polymer matrix composite 442 (HB26 grade Dyneema ${ }^{\circledR}$ ) has been studied using model test structures that enabled control of the 443 spatial distribution and velocity of ejecta. The Dyneema ${ }^{\circledR}$ laminate encased an aluminum alloy 444 sandwich panel whose hybrid corrugated cores contained alumina prisms. It has been found that: 445 1. Self-gripping, Dyneema ${ }^{\circledR}$ encased targets were not penetrated when a 12.7 mm diameter $446 \quad$ hardened chrome steel sphere impacted the base of the center prism at a velocity $\mathrm{Vi} \geq 2.7$ 
$\mathrm{km} \mathrm{s}^{-1}$. This corresponded to at least a $100 \%$ increase in the ballistic limit compared to a target that had the same laminate encasement and areal density, but used a solid aluminum plate to interact with the projectile.

\section{Acknowledgements}

468 and for providing the Dyneema ${ }^{\circledR}$ HB26 material used in the study. We thank Timothy Schmidt 469 (Trilion Quality Systems) for assistance with the 3D-DIC system. The research was co-funded by 
470 the Office of Naval Research (ONR) under grant number N00014-07-1-0764 (Program manager,

471 Dr. D. Shifler) and the Defense Advanced Research Projects Agency (DARPA) under grant

472 number W91CRB-11-1-0005 (Program manager, Dr. J. Goldwasser). Dyneema ${ }^{\circledR}$ is a trademark

473 of DSM. Use of this trademark is strictly prohibited unless authorized.

474

475 Citations

476 [1] O'Masta MR, Deshpande VS, Wadley HNG. Mechanisms of projectile penetration in

477 Dyneema ${ }^{\circledR}$ encapsulated aluminum structures. International Journal of Impact Engineering

$478 \quad$ 2014;74:16-35. doi:10.1016/j.ijimpeng.2014.02.002.

479 [2] Hogg PJ. Composites in Armor. Science 2006;314:1100-1. doi:10.1126/science.1131118.

480 [3] Fink BK. Performance Metrics for Composite Integral Armor. Journal of Thermoplastic

481 Composite Materials 2000;13:417-31. doi:10.1106/FR0L-T33W-JPD0-VFH3.

482 [4] Vargas-Gonzalez LR, Walsh SM, Scott BR. Balancing ballistic and back-face deformation

483 in helmets: the role of alternative resisns, fibers, and fiber architecture in mass-efficient

484 head protection. In: Baker E, Templeton D, editors. Proceedings of the 26th International

485 Symposium on Ballistics, vol. 2, Miami, FL: DEStech Publications, Inc.; 2011, p. 1872-82.

486 [5] Phoenix SL, Porwal PK. A new membrane model for the ballistic impact response and V50

487 performance of multi-ply fibrous systems. International Journal of Solids and Structures

$488 \quad 2003 ; 40: 6723-65$. doi:10.1016/S0020-7683(03)00329-9.

489 [6] Karthikeyan K, Russell BP, Fleck NA, Wadley HNG, Deshpande VS. The effect of shear

490 strength on the ballistic response of laminated composite plates. European Journal of

491 Mechanics - A/Solids 2013;42:35-53. doi:10.1016/j.euromechsol.2013.04.002. 
492 [7] Parsons EM, Weerasooriya T, Sarva S, Socrate S. Impact of woven fabric: Experiments and 493 mesostructure-based continuum-level simulations. Journal of the Mechanics and Physics of 494 Solids 2010;58:1995-2021. doi:10.1016/j.jmps.2010.05.006.

495 [8] Vargas-Gonzalez L, Walsh SM, Wolbert J. Impact and Ballistic Response of Hybridized Thermoplastic Laminates. Aberdeen Proving Ground, MD: Army Research Laboratory; 2011.

[9] Lee BL, Song JW, Ward JE. Failure of Spectra® Polyethylene Fiber-Reinforced Composites under Ballistic Impact Loading. Journal of Composite Materials 1994;28:120226. doi:10.1177/002199839402801302.

[10] Chocron S, King N, Bigger R, Walker JD, Heisserer U, van der Werff H. Impacts and Waves in Dyneema® HB80 Strips and Laminates. J Appl Mech 2013;80:031806-1 - 10. doi:10.1115/1.4023349.

504 [11] Iremonger MJ. Polyethylene composites for protection against high velocity small arms 505 bullets. In: Reinecke WG, editor. Proceedings of the 18th International Symposium on Ballistics, San Antonio, TX: 1999, p. 946-54.

[12] Scott BR. The penetration of compliant laminates by compact projectiles. Proceedings of the 18th International Symposium on Ballistics, San Antonio, TX: 1999, p. 1184-91.

511 [14] Grujicic M, Arakere G, He T, Bell WC, Cheeseman BA, Yen C-F, et al. A ballistic material 512 model for cross-plied unidirectional ultra-high molecular-weight polyethylene fiberreinforced armor-grade composites. Materials Science and Engineering: A 2008;498:23141. doi:10.1016/j.msea.2008.07.056. 
515 [15] Greenhalgh ES, Bloodworth VM, Iannucci L, Pope D. Fractographic observations on

516 Dyneema ${ }^{\circledR}$ composites under ballistic impact. Composites Part A: Applied Science and

517 Manufacturing 2013;44:51-62. doi:10.1016/j.compositesa.2012.08.012.

518 [16] Woodward RL, Egglestone GT, Baxter BJ, Challis K. Resistance to penetration and

519 compression of fibre-reinforced composite materials. Composites Engineering 1994;4:329-

520 41. doi:10.1016/0961-9526(94)90083-3.

521 [17] Scott BR, Cheeseman BA. The Mechanics of Projectile Arrest for Compliant Cross Plied

522 Unidirectional Laminates. vol. Vol. 2, New Orleans, LA: 2008.

523 [18] Heisserer U, van der Werff H, Hendrix J. Ballistic Depth of Penetration Studies in

524 Dyneema ${ }^{\circledR}$ Composites. In: Wickert M, Salk M, editors. Proceedings of the 27th

525 International Symposium on Ballistics, vol. 2, Freiburg, Germany: DEStech Publications, $526 \quad$ Inc.; 2013, p. 1936-43.

527 [19] Attwood JP, Khaderi SN, Karthikeyan K, Fleck NA, O’Masta MR, Wadley HNG, et al. The

528 out-of-plane compressive response of composites. Journal of the Mechanics and Physics of $529 \quad$ Solids n.d. doi:10.1016/j.jmps.2014.05.017.

530 [20] O’Masta MR, Deshpande VS, Wadley HNG. Defect controlled transverse compressive 531 strength of polyethylene fiber laminates. International Journal of Solids and Structures $532 \quad$ 2015;52:130-49. doi:10.1016/j.ijsolstr.2014.09.023.

533 [21] Chapman DJ, Braithwaite CH, Proud WG. The Response of Dyneema to Shock-Loading. $534 \quad$ AIP Conference Proceedings 2009;1195:1269-72. doi:doi:10.1063/1.3295037.

535 [22] Hazell PJ, Appleby-Thomas GJ, Trinquant X, Chapman DJ. In-fiber shock propagation in 536 Dyneema®. J Appl Phys 2011;110:043504-1 - 043504-5. doi:doi:10.1063/1.3622294. 
537 [23] Karthikeyan K, Russell BP. Polyethylene ballistic laminates: Failure mechanics and 538 interface effect. Materials \& Design 2014;63:115-25. doi:10.1016/j.matdes.2014.05.069.

539 [24] Cunniff PM. Dimensionless parameters for optimization of textile-based body armor $540 \quad$ systems. In: Reinecke WG, editor. Proceedings of the 18th International Symposium on 541 Ballistics, San Antonio, TX: Technomic Publishing Company, Inc; 1999, p. 1303-10.

542 [25] Karthikeyan K, Russell BP, Fleck NA, O’Masta MR, Wadley HNG, Deshpande VS. The 543 soft impact response of composite laminate beams. International Journal of Impact $544 \quad$ Engineering 2013;60:24-36. doi:10.1016/j.ijimpeng.2013.04.002.

545 [26] Dehn JT. A unified theory of penetration. Aberdeen Proving Ground, MD: Ballistic $546 \quad$ Research Laboratory; 1986.

547 [27] Yungwirth CJ, Radford DD, Aronson M, Wadley HNG. Experiment assessment of the 548 ballistic response of composite pyramidal lattice truss structures. Composites Part B: Engineering 2008;39:556-69. doi:10.1016/j.compositesb.2007.02.029.

550 [28] Yungwirth CJ, O’Connor J, Zakraysek A, Deshpande VS, Wadley HNG. Explorations of Hybrid Sandwich Panel Concepts for Projectile Impact Mitigation. Journal of the American

553 [29] Ni CY, Li YC, Xin FX, Jin F, Lu TJ. Ballistic resistance of hybrid-cored sandwich plates:

554 Numerical and experimental assessment. Composites Part A: Applied Science and 555 Manufacturing 2013;46:69-79. doi:10.1016/j.compositesa.2012.07.019.

556 [30] Wadley HNG, Dharmasena KP, O’Masta MR, Wetzel JJ. Impact response of aluminum 557 corrugated core sandwich panels. International Journal of Impact Engineering 558 2013;62:114-28. doi:10.1016/j.ijimpeng.2013.06.005. 
559 [31] Wadley HNG, O’Masta MR, Dharmasena KP, Compton BG, Gamble EA, Zok FW. Effect

560 of core topology on projectile penetration in hybrid aluminum/alumina sandwich structures.

561 International Journal of Impact Engineering 2013;62:99-113.

562 doi:10.1016/j.ijimpeng.2013.05.008.

563 [32] Russell BP, Karthikeyan K, Deshpande VS, Fleck NA. The high strain rate response of

564 Ultra High Molecular-weight Polyethylene: From fibre to laminate. International Journal of

565 Impact Engineering 2013;60:1-9. doi:10.1016/j.jimpeng.2013.03.010.

566 [33] Schmidt TE, Tyson J, Galanulis K, Revilock DM, Melis ME. Full-field dynamic

567 deformation and strain measurements using high-speed digital cameras. Proc. SPIE, vol.

568 5580, Alexandria, VA: 2005, p. 174-85. doi:10.1117/12.567142.

569 [34] Yu JH, Dehmer PG. Dynamic Impact Deformation Analysis Using High-speed Cameras

570 and ARAMIS Photogrammetry Software. Aberdeen Proving Ground, MD: Army Research

$571 \quad$ Laboratory; 2010.

572 [35] Hisley DM, Gurganus JC, Drysdale AW. Experimental Methodology Using Digital Image

573 Correlation to Assess Ballistic Helmet Blunt Trauma. J Appl Mech 2011;78:051022-

$574 \quad$ 051022. doi:10.1115/1.4004332.

575 [36] Compton BG, Gamble EA, Zok FW. Failure initiation during impact of metal spheres onto

576 ceramic targets. International Journal of Impact Engineering 2013;55:11-23.

577 doi:10.1016/j.jimpeng.2012.12.002.

578 
(a) Encased aluminum target

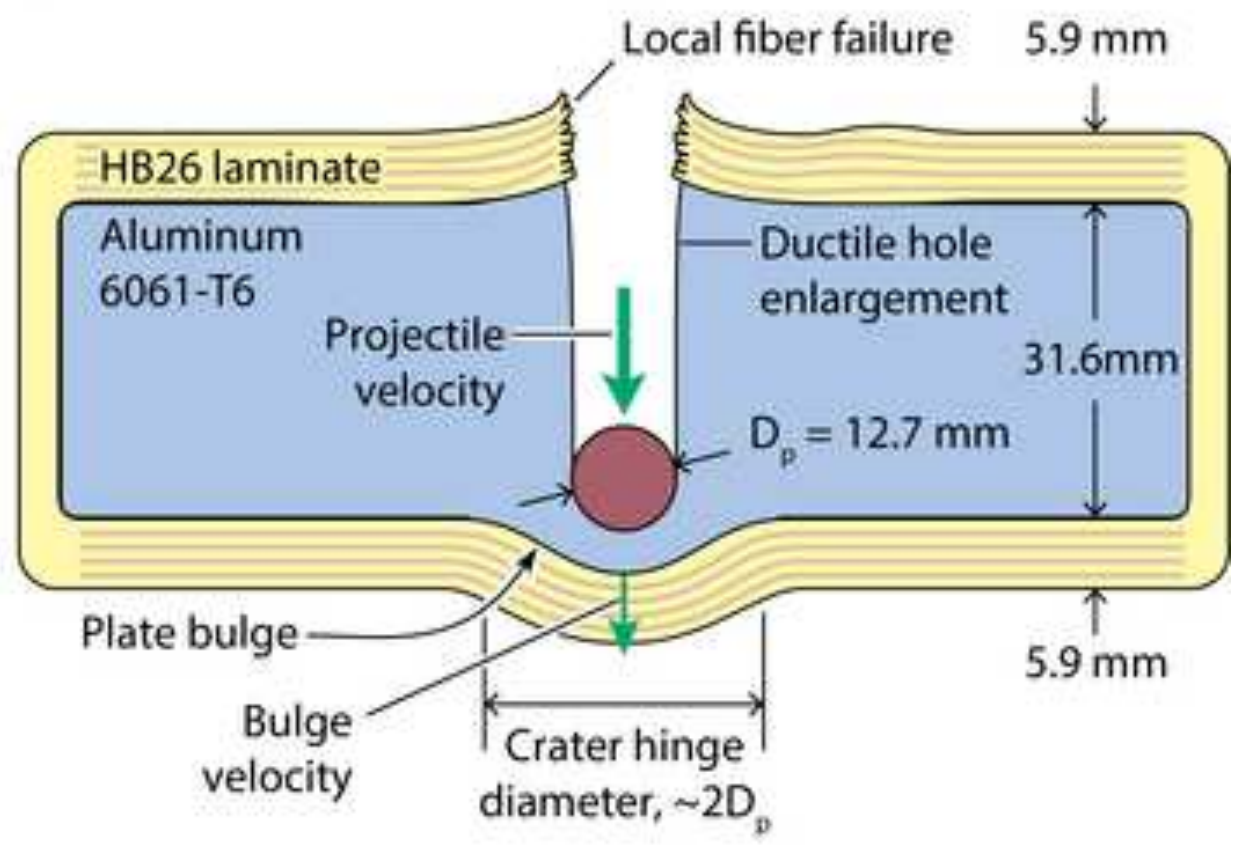

(b) Intact projectile impact

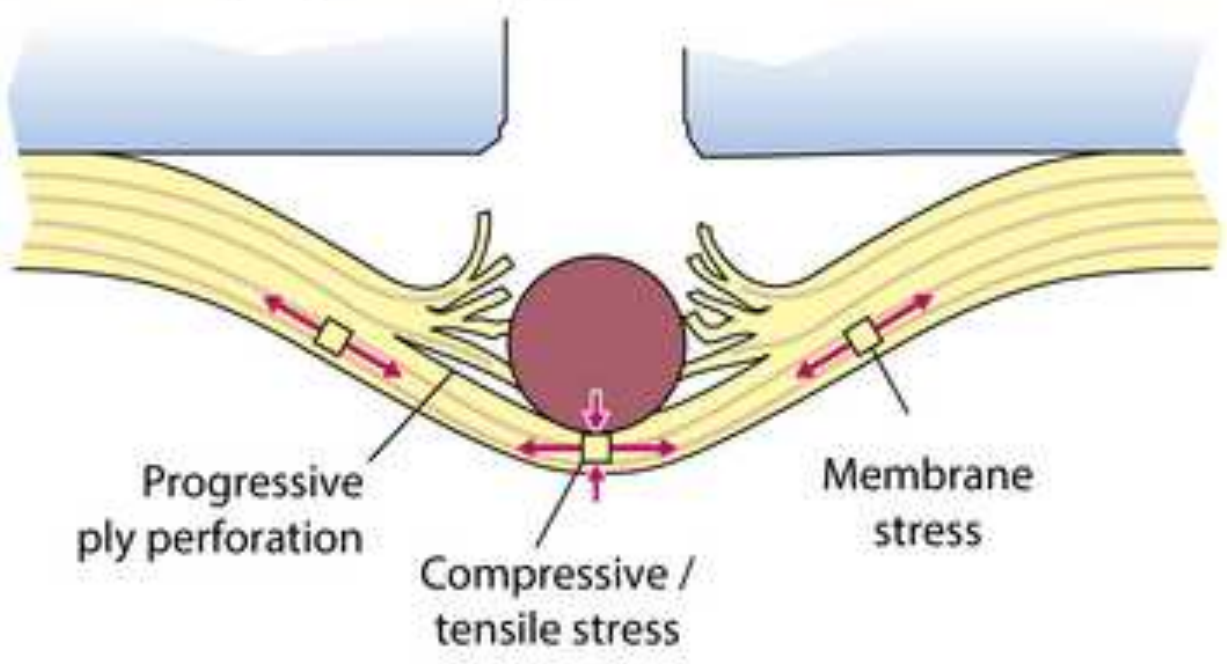

(c) Fragmented projectile impact

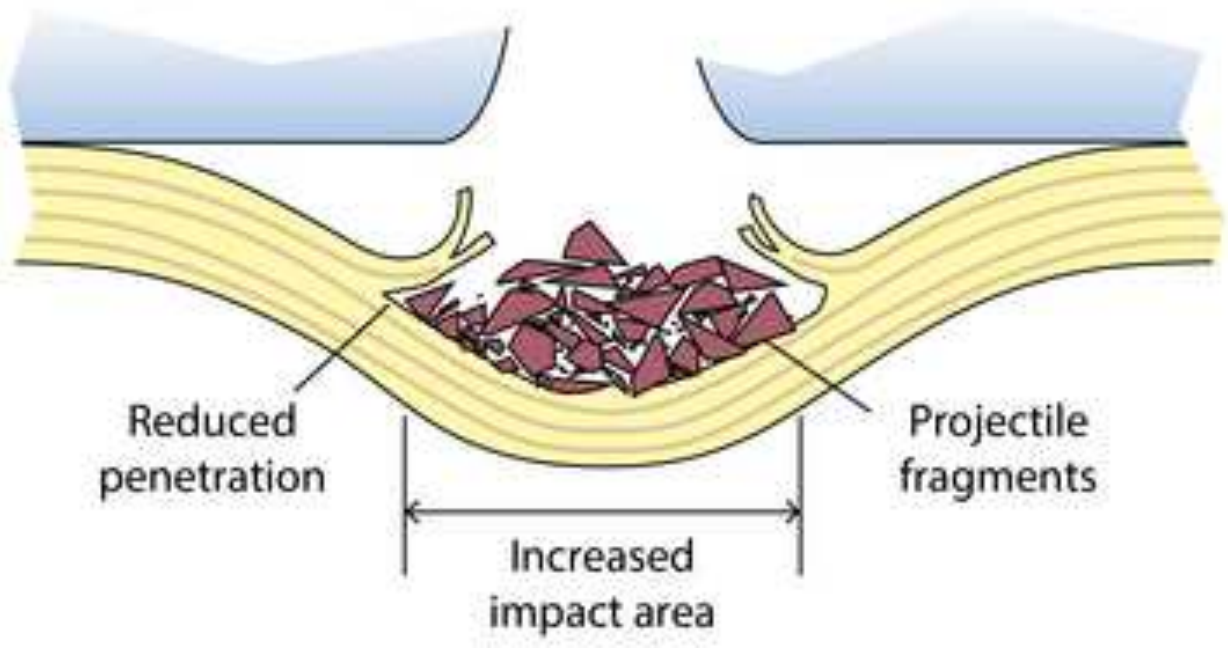


(a) Prism base impact

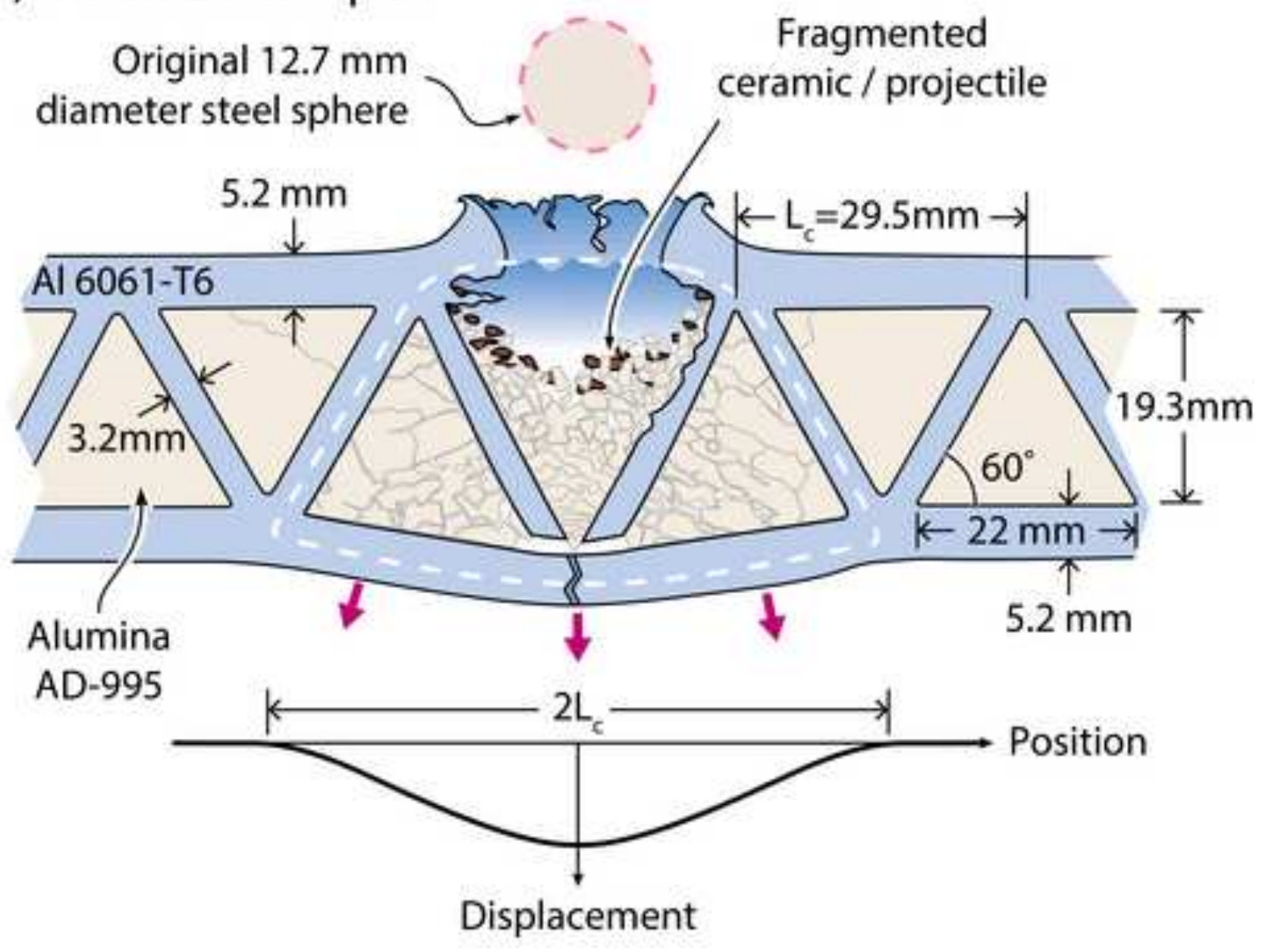

(b) Prism apex impact

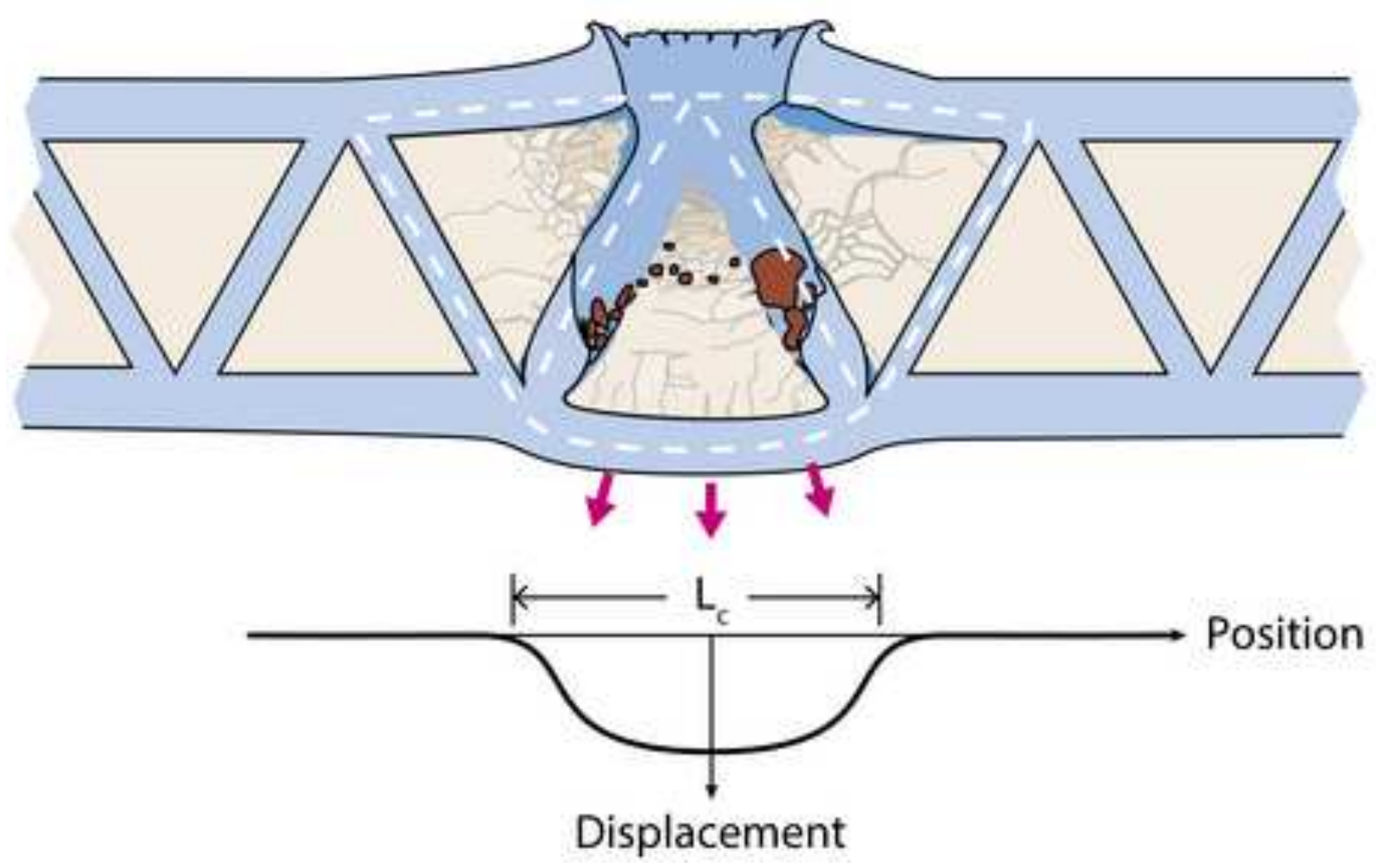


(a) Encased hybrid

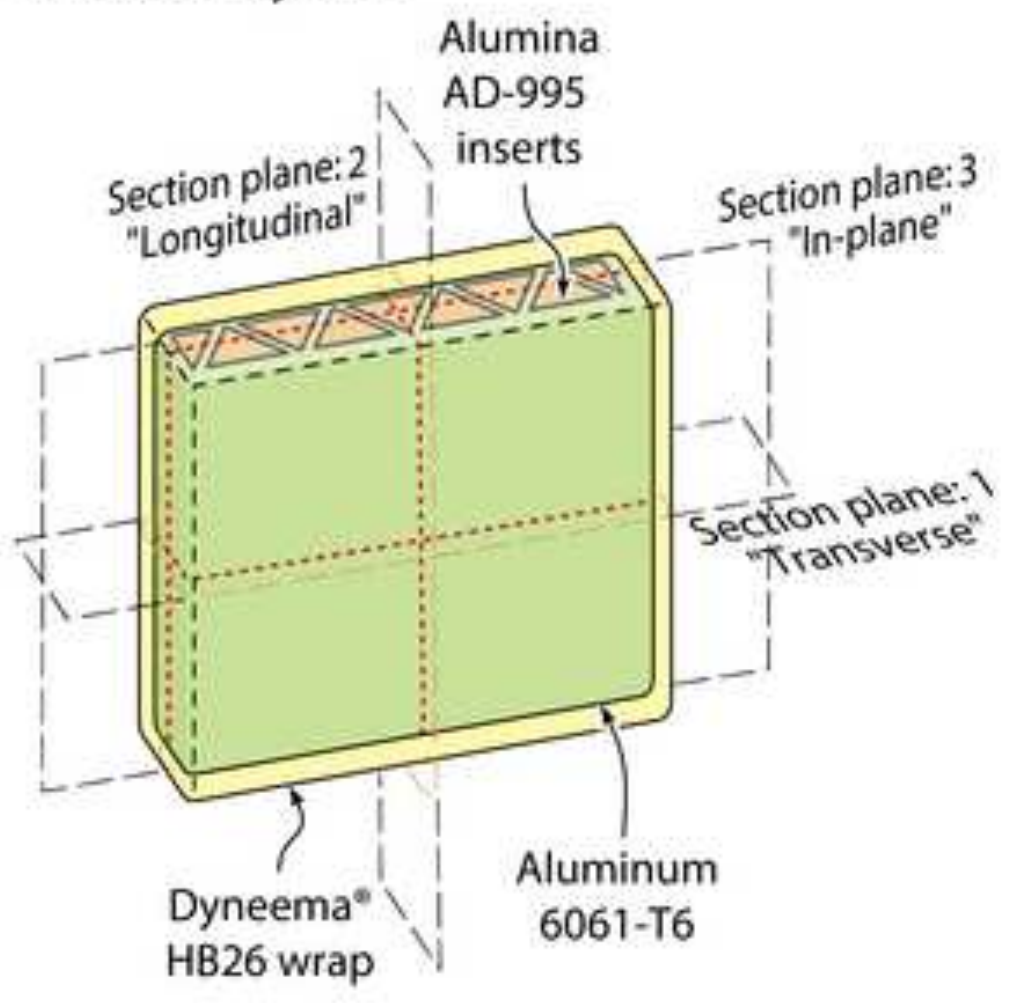

(b) Encased hybrid cross-section

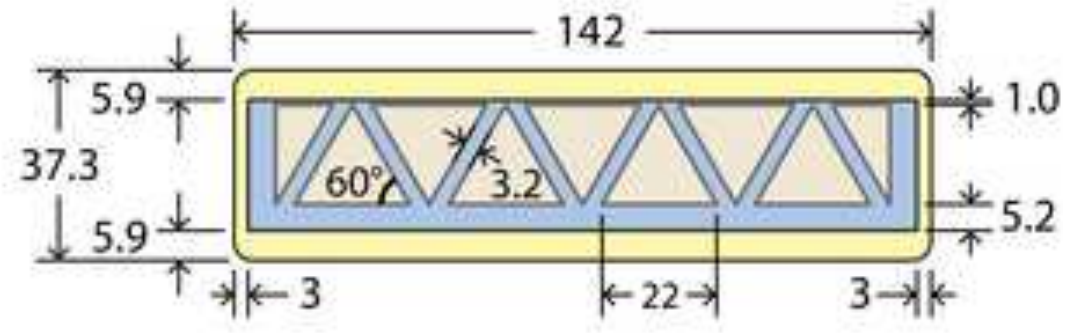

(c) Rear face cutout

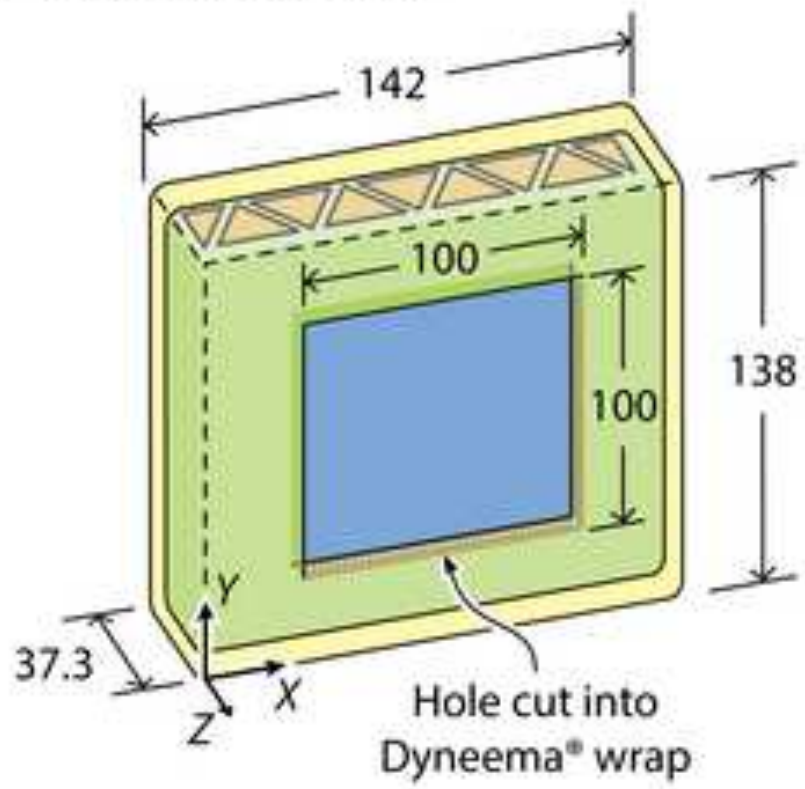

All dimensions in millimeters 

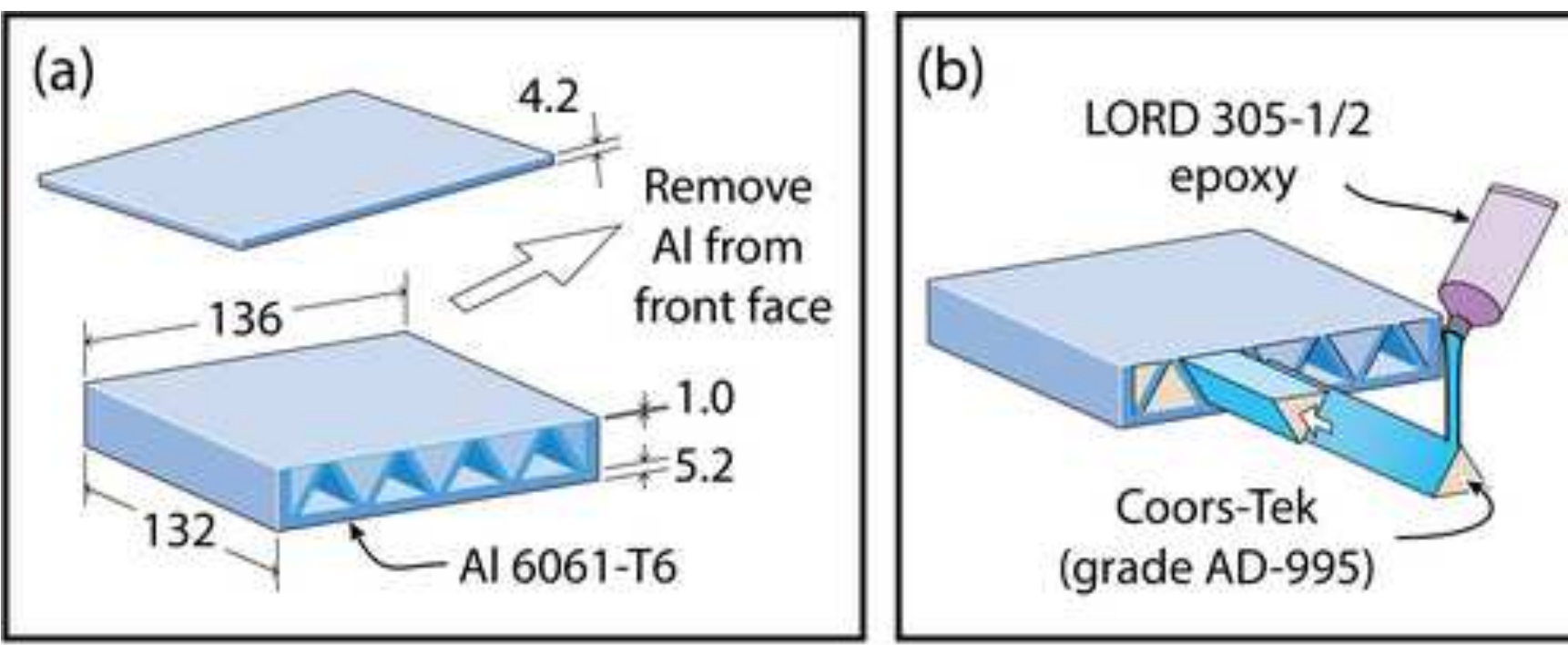

(c)

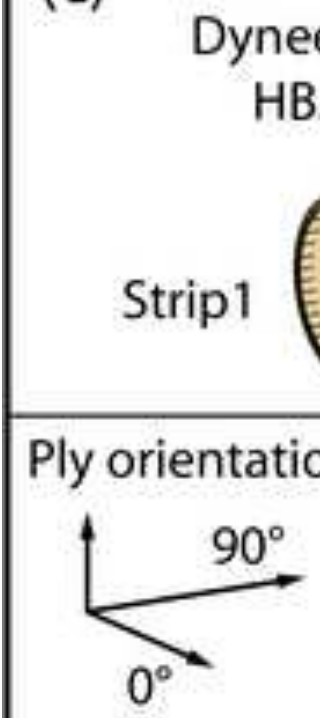

Wrap Dyneema ${ }^{\circ}$ around plate, alternating strips 1 and 2 .

(d)

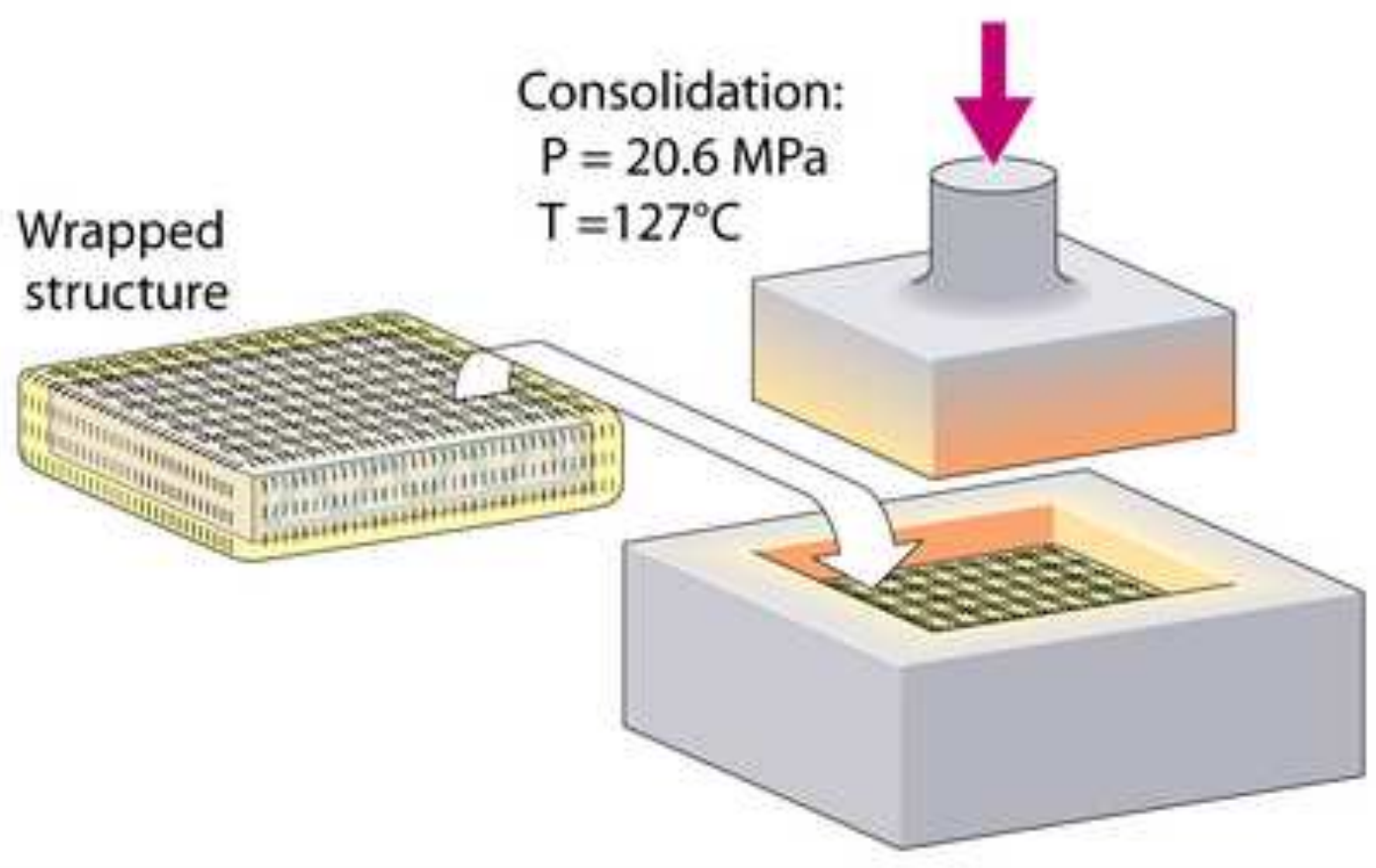




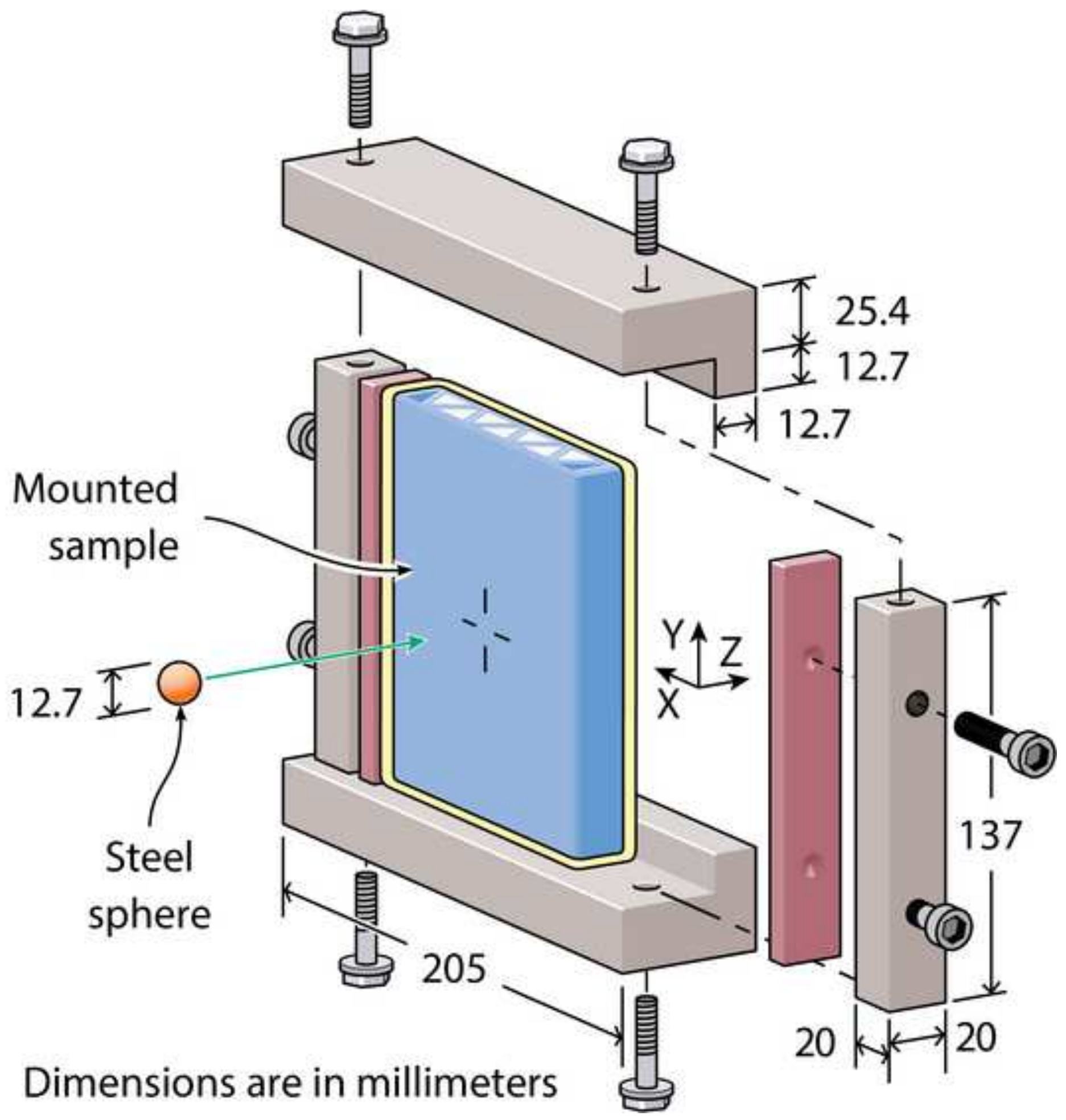




\section{(a) Top view}

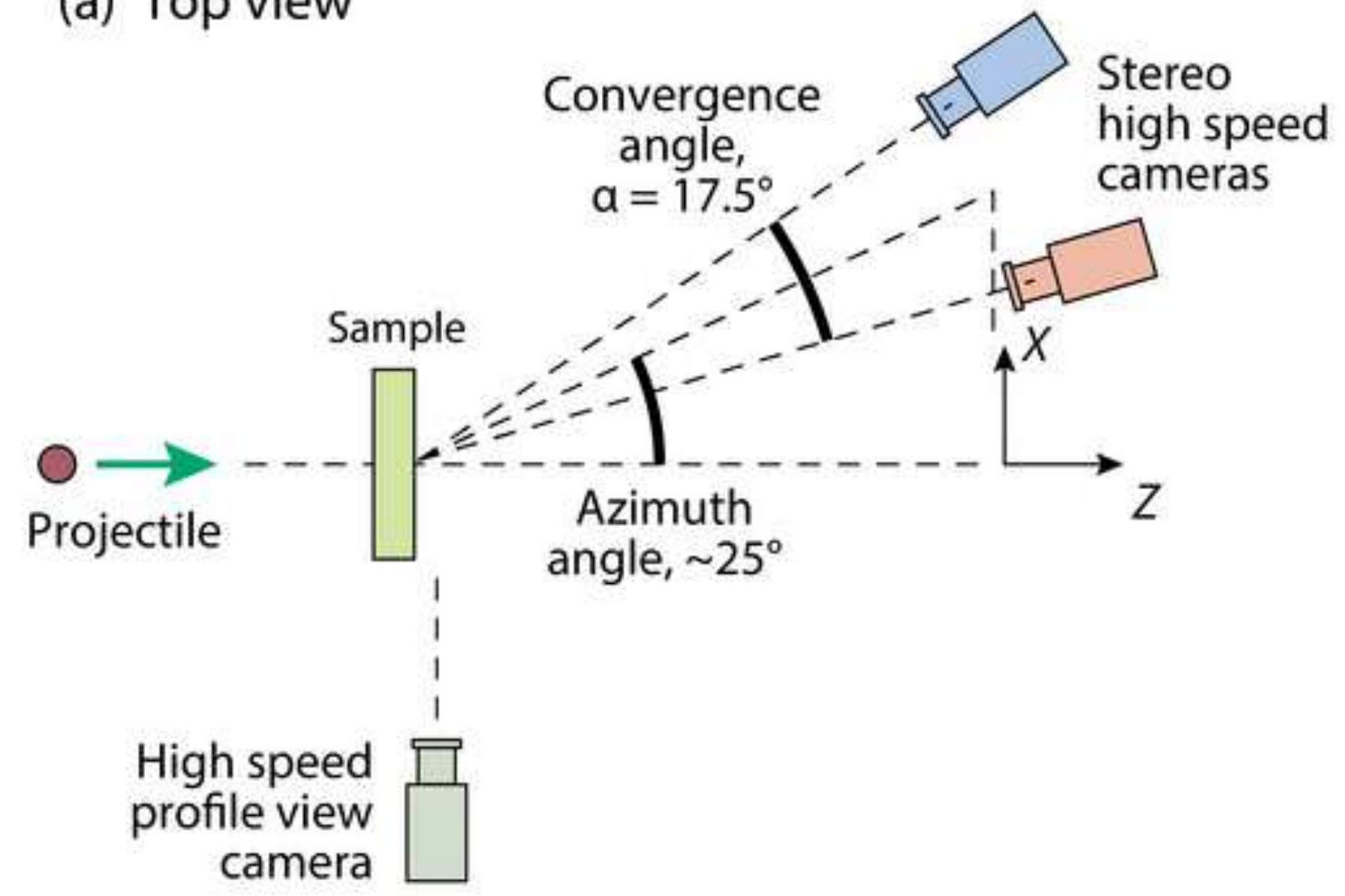

(b) Rear perspective view

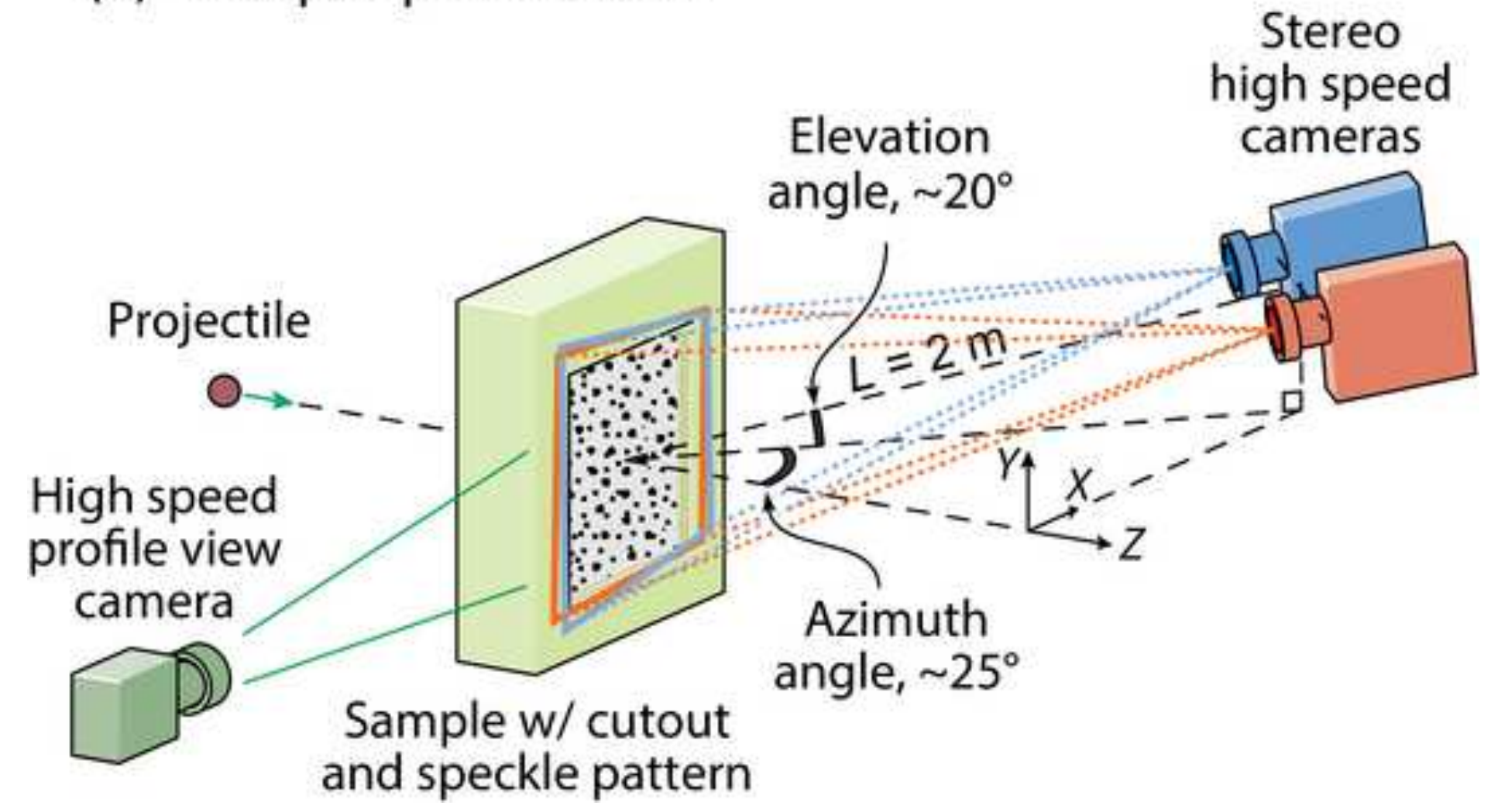



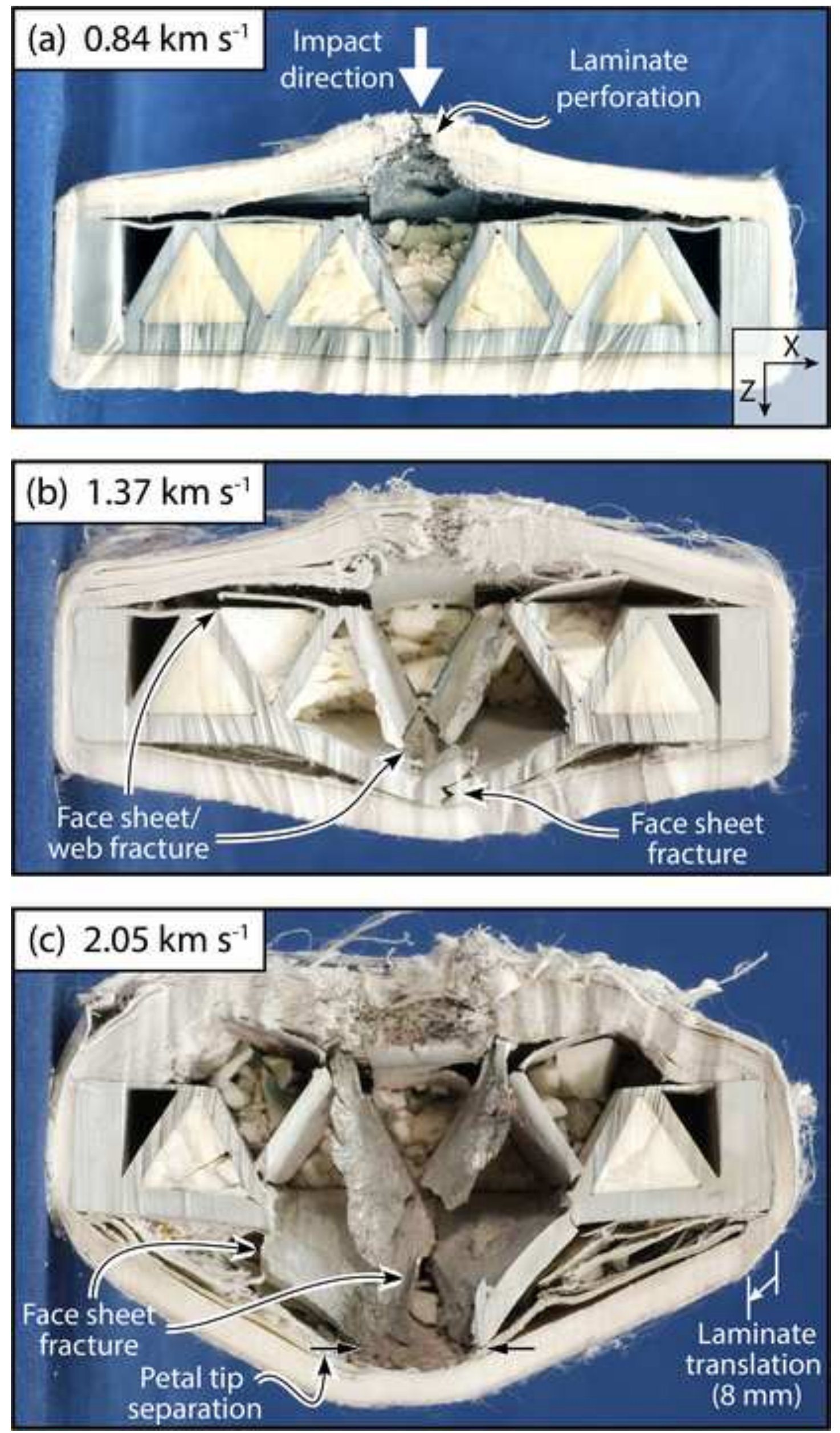


$$
V i=1.37 \mathrm{~km} \mathrm{~s}^{-1}
$$
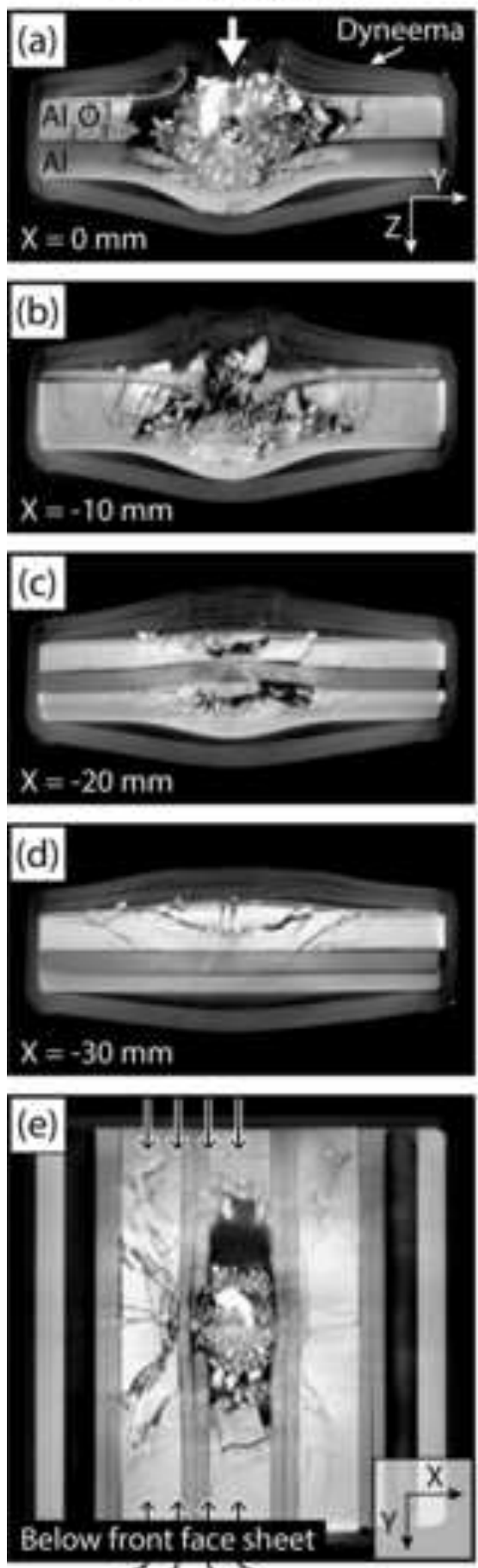

(d) (c) (b) (a)

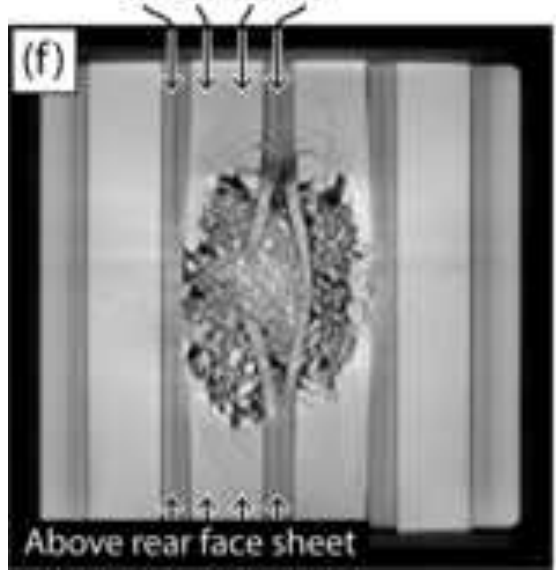

$$
\mathrm{Vi}=2.26 \mathrm{~km} \mathrm{~s}^{-1}
$$
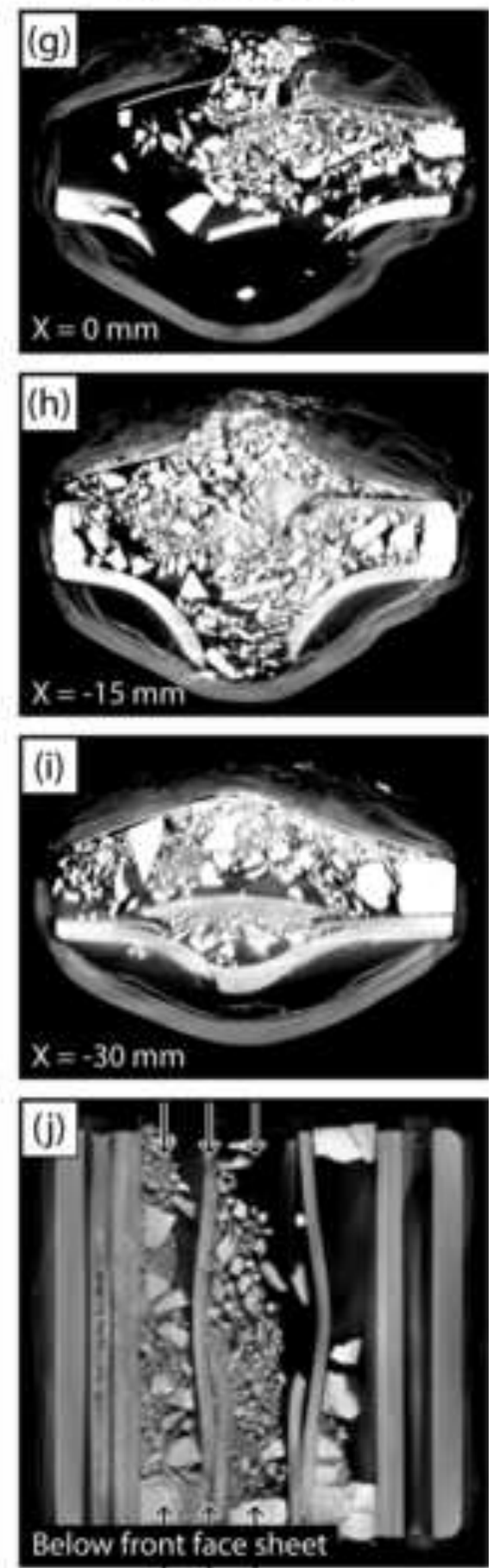

(i) (h) (g)

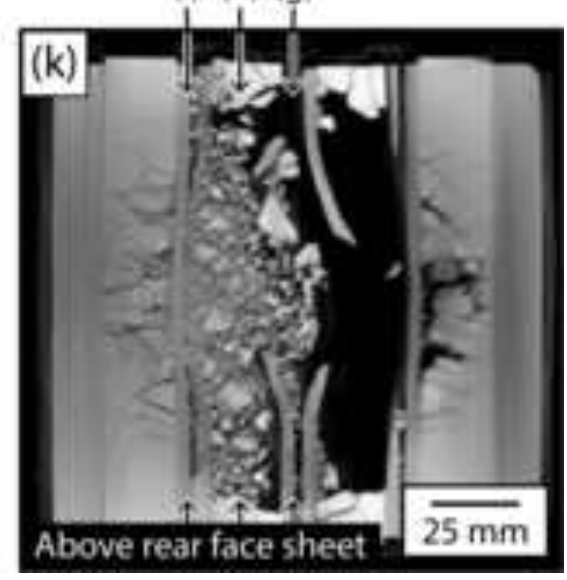



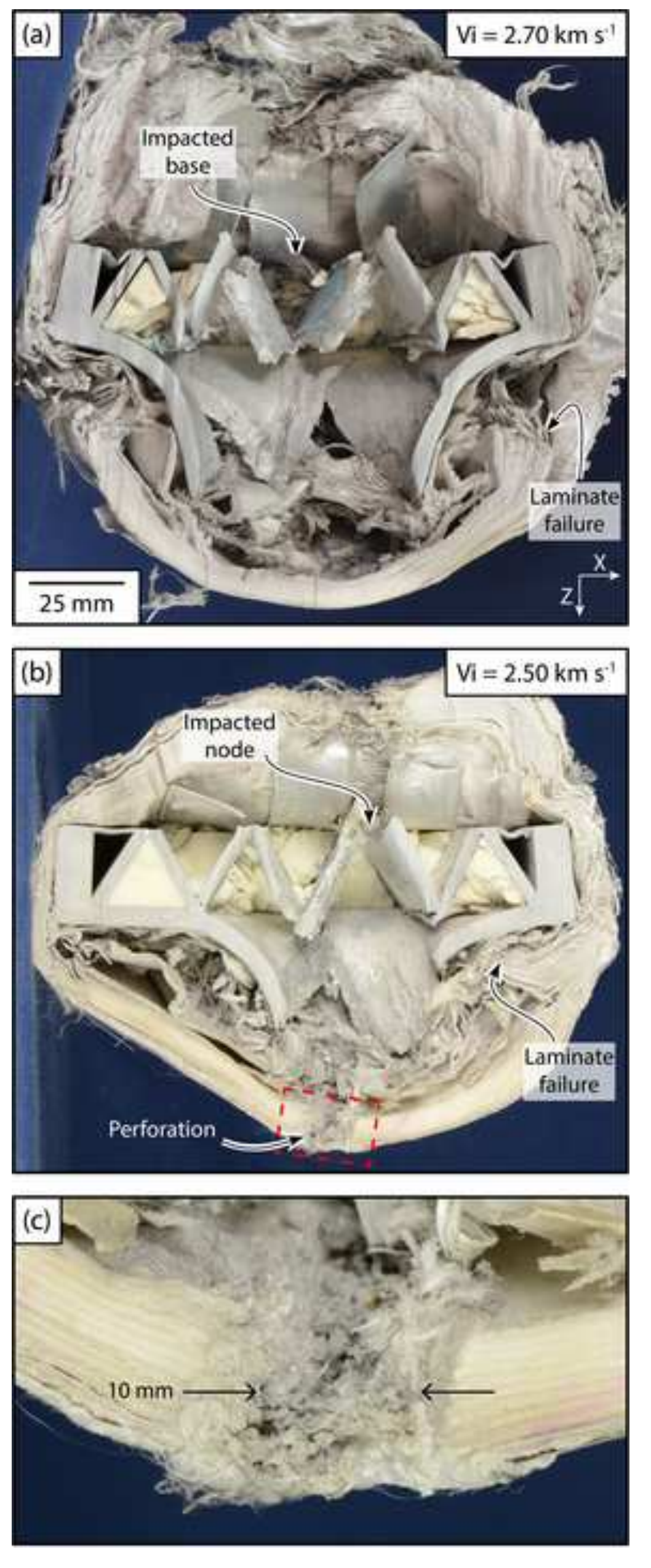

Figure 9

\section{.}

Figure 9

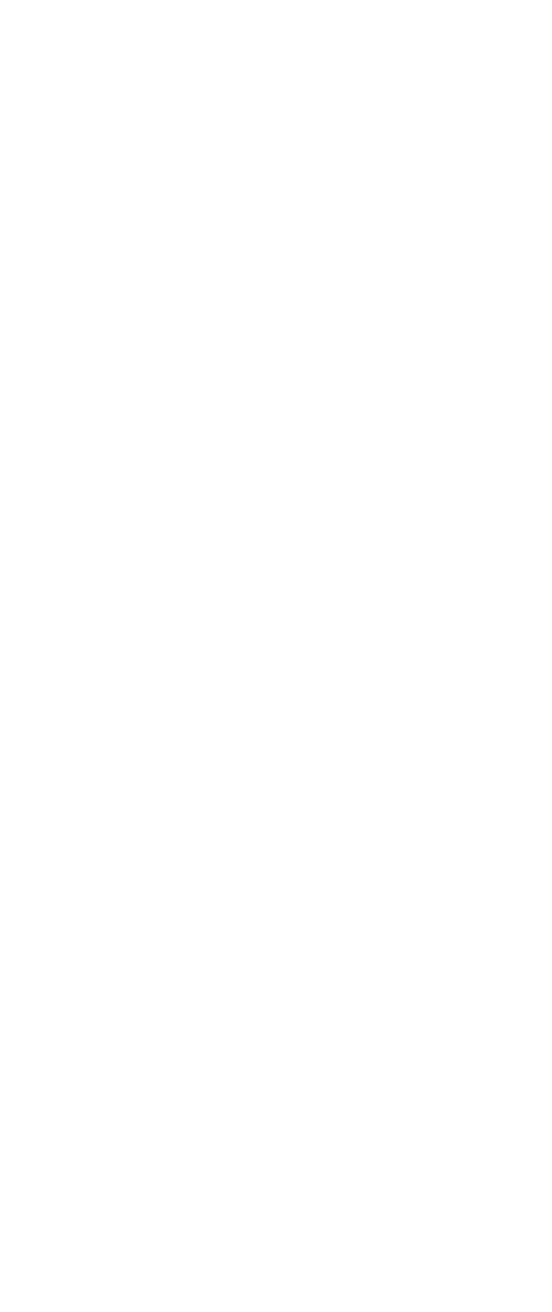

$$
\text { . }
$$
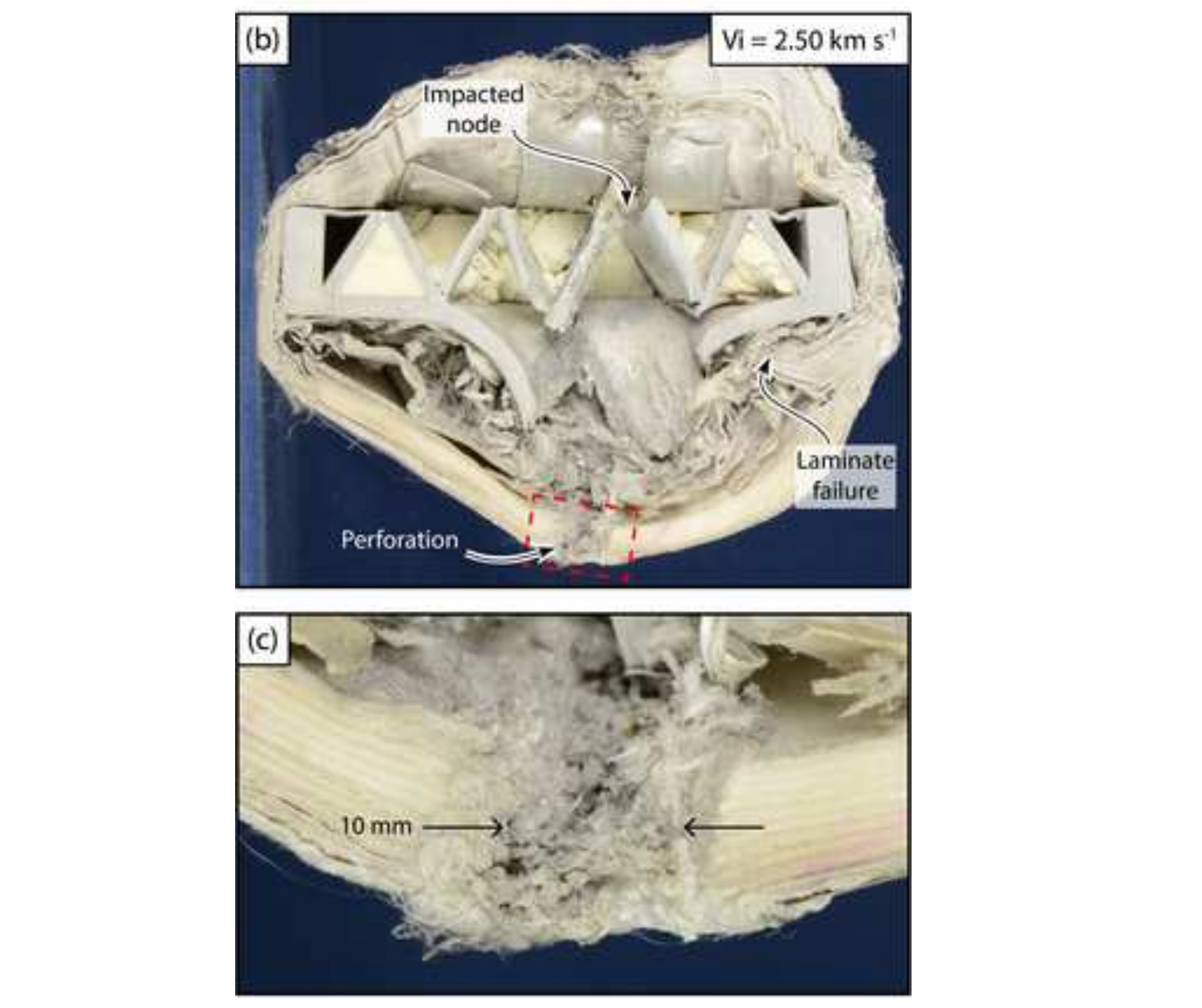

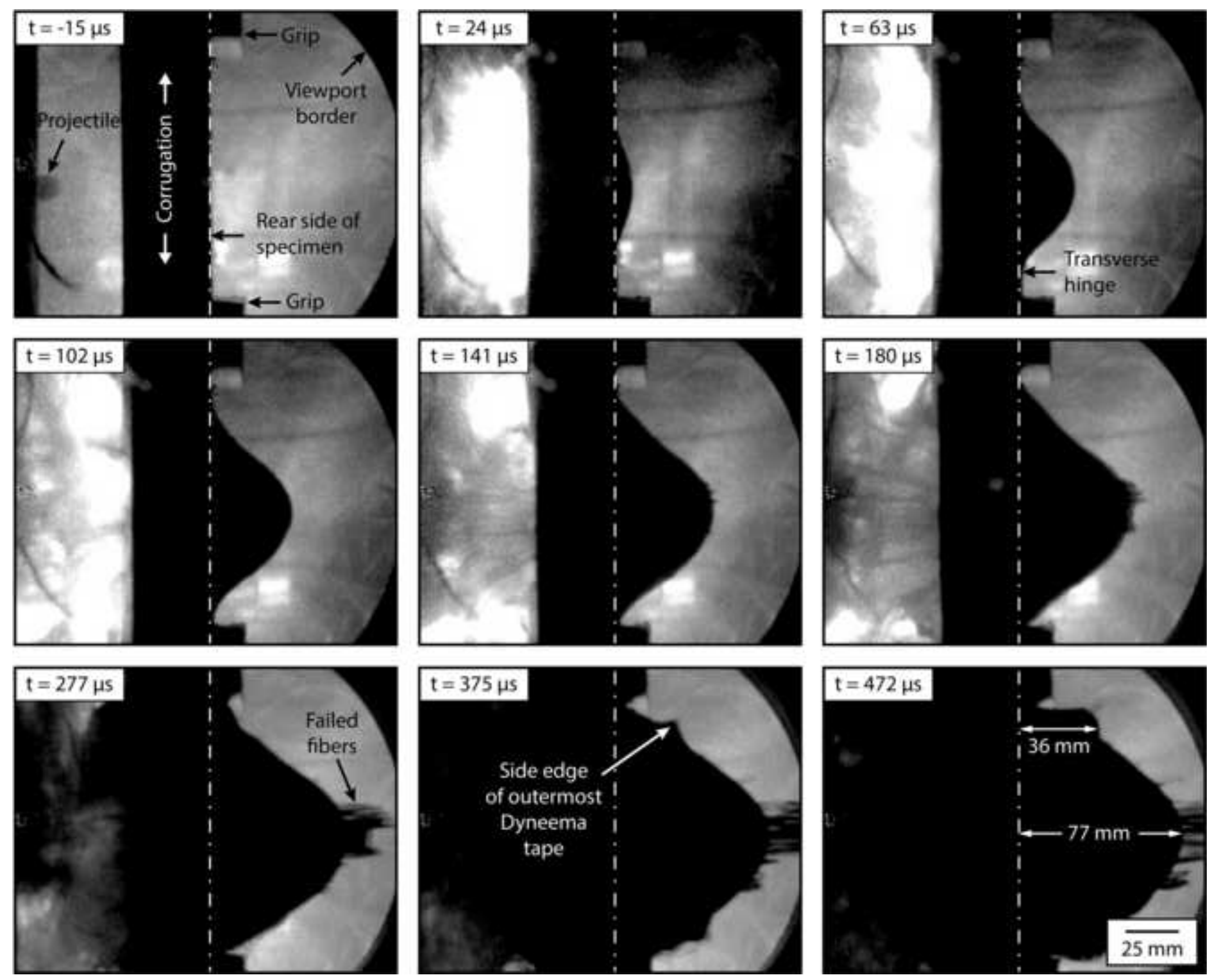
(a) Oblique rear view with velocity overlay

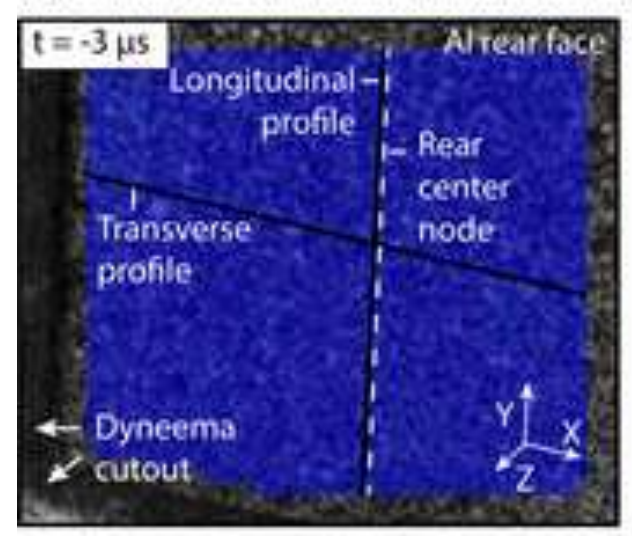
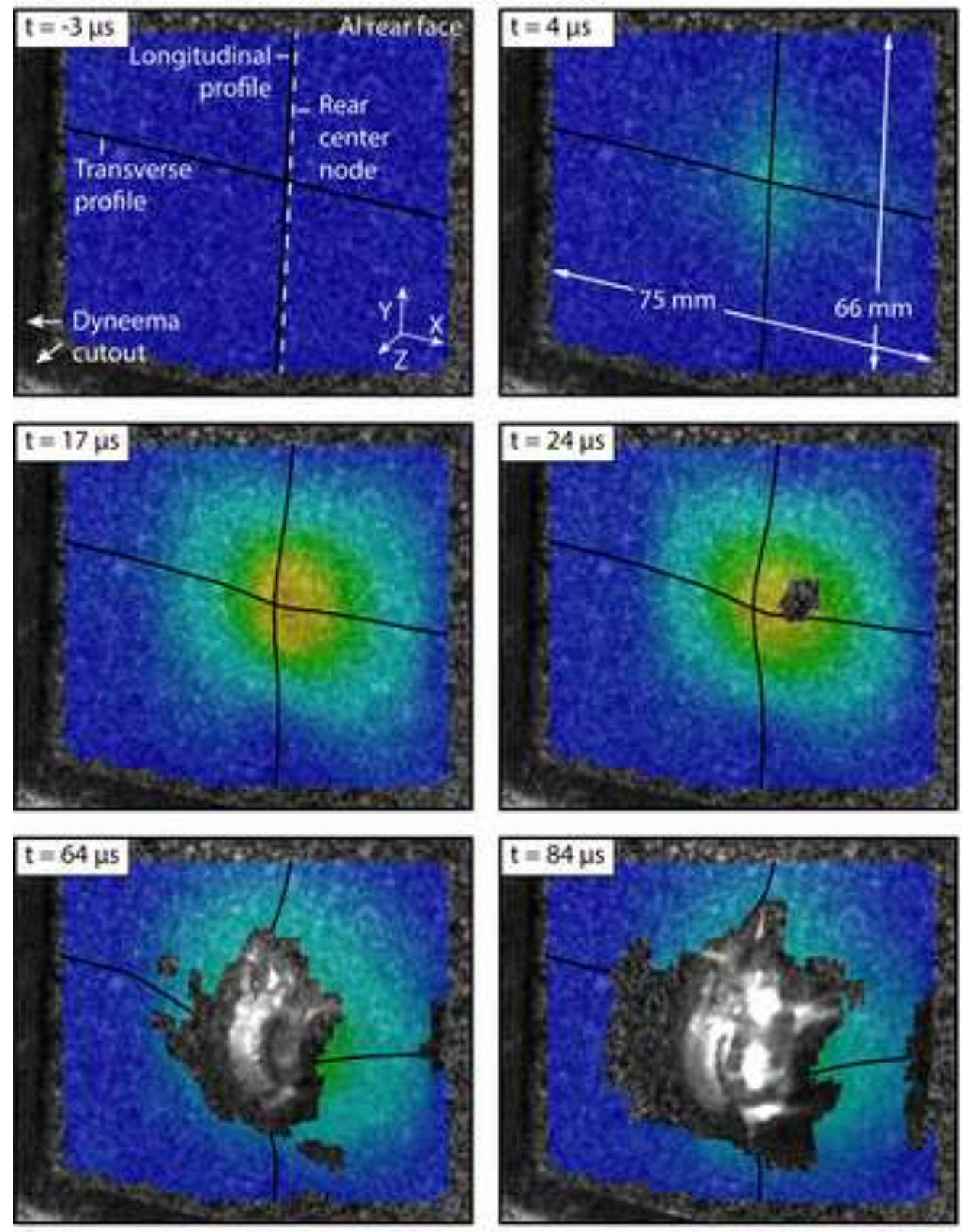

(b) Profile view
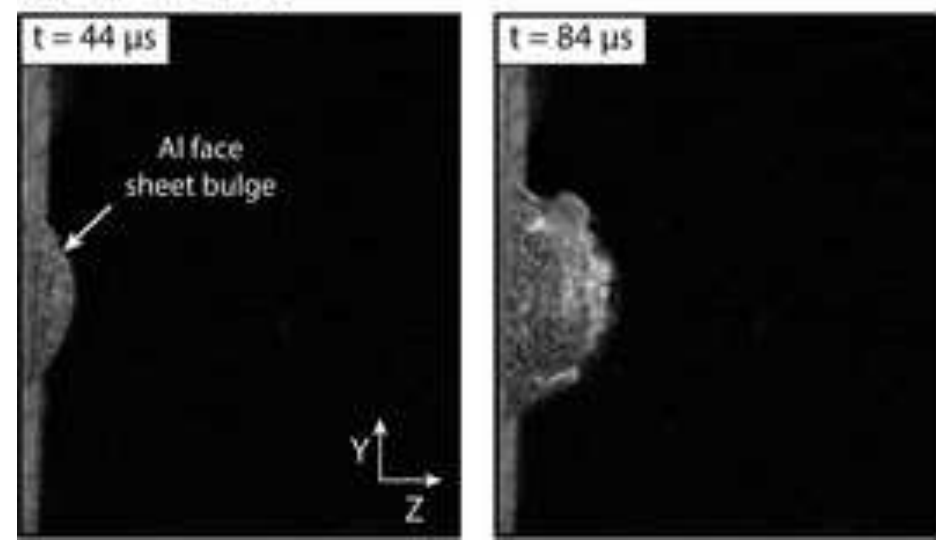
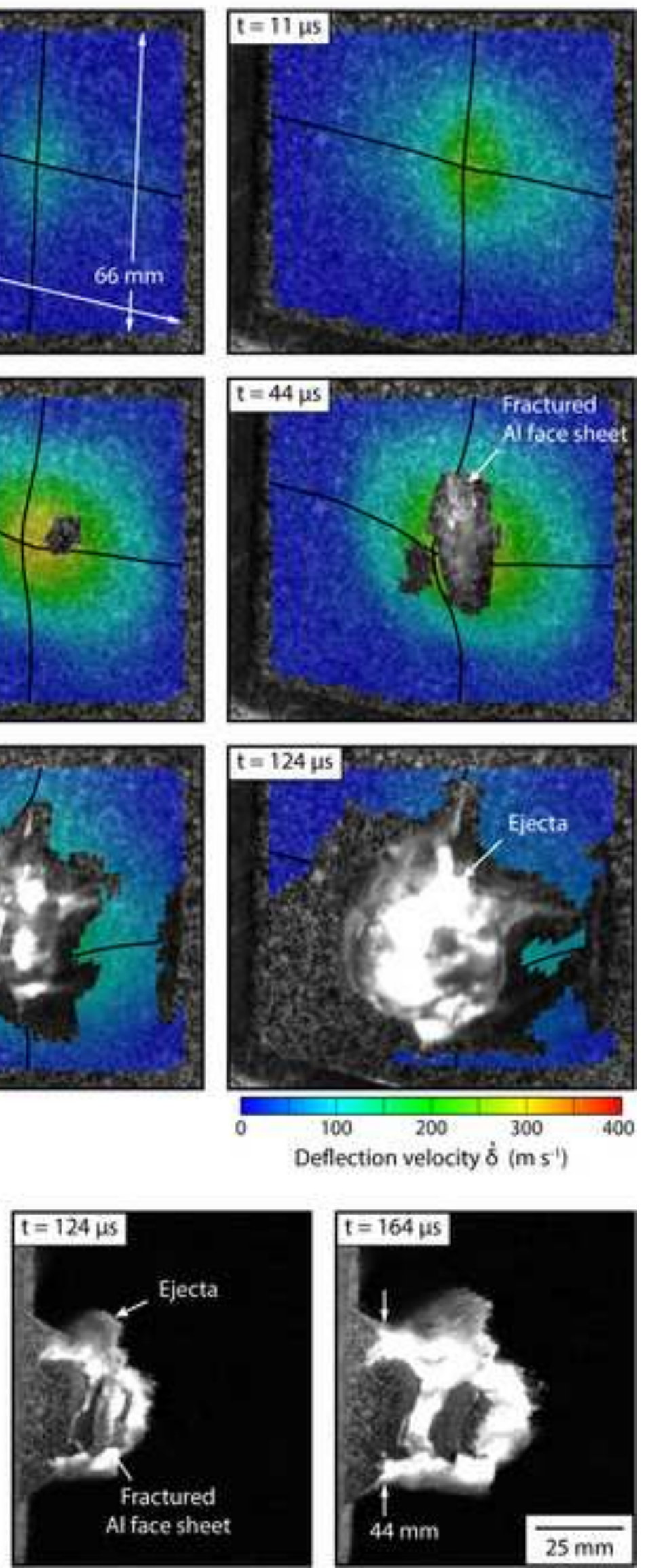

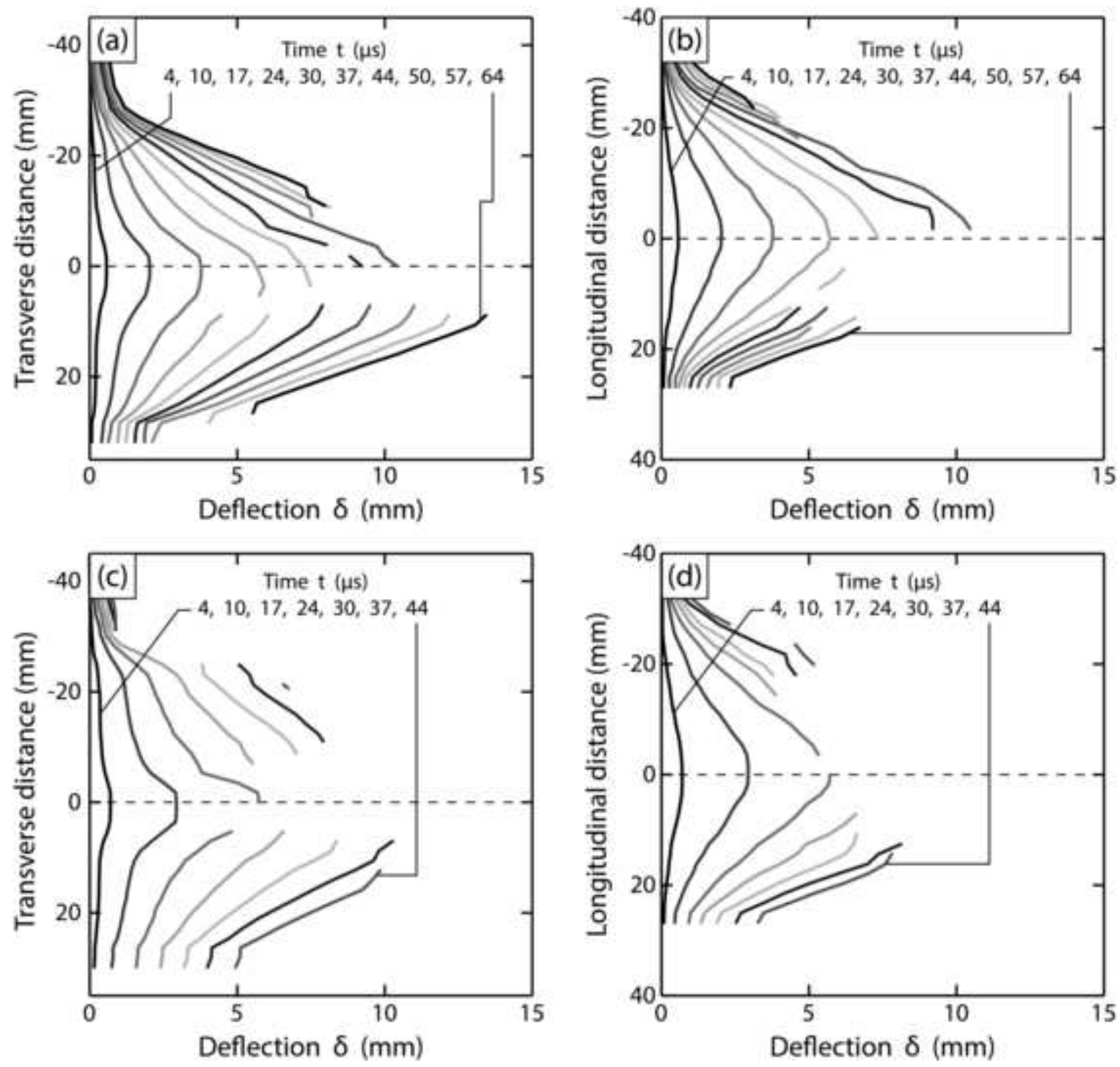


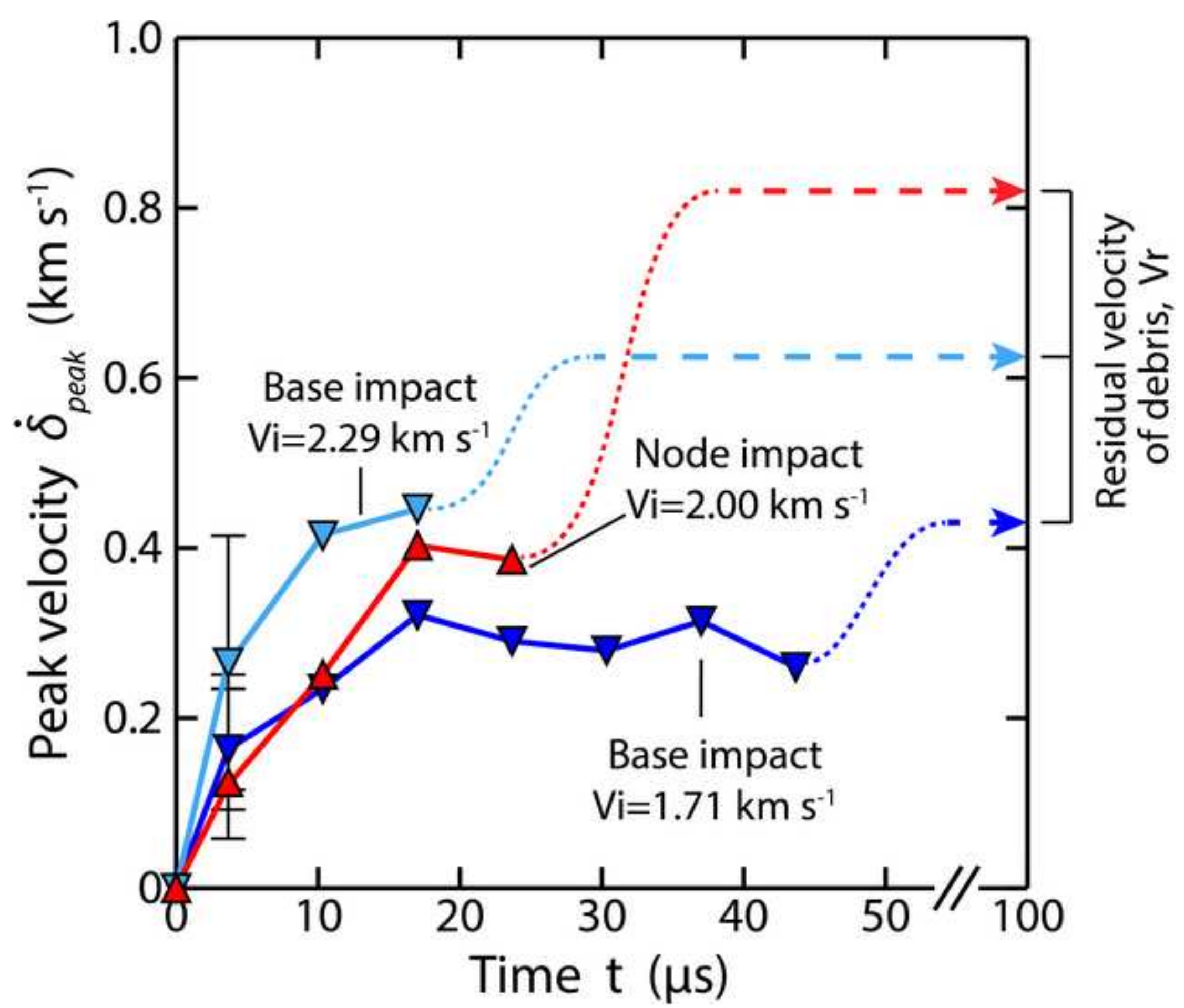




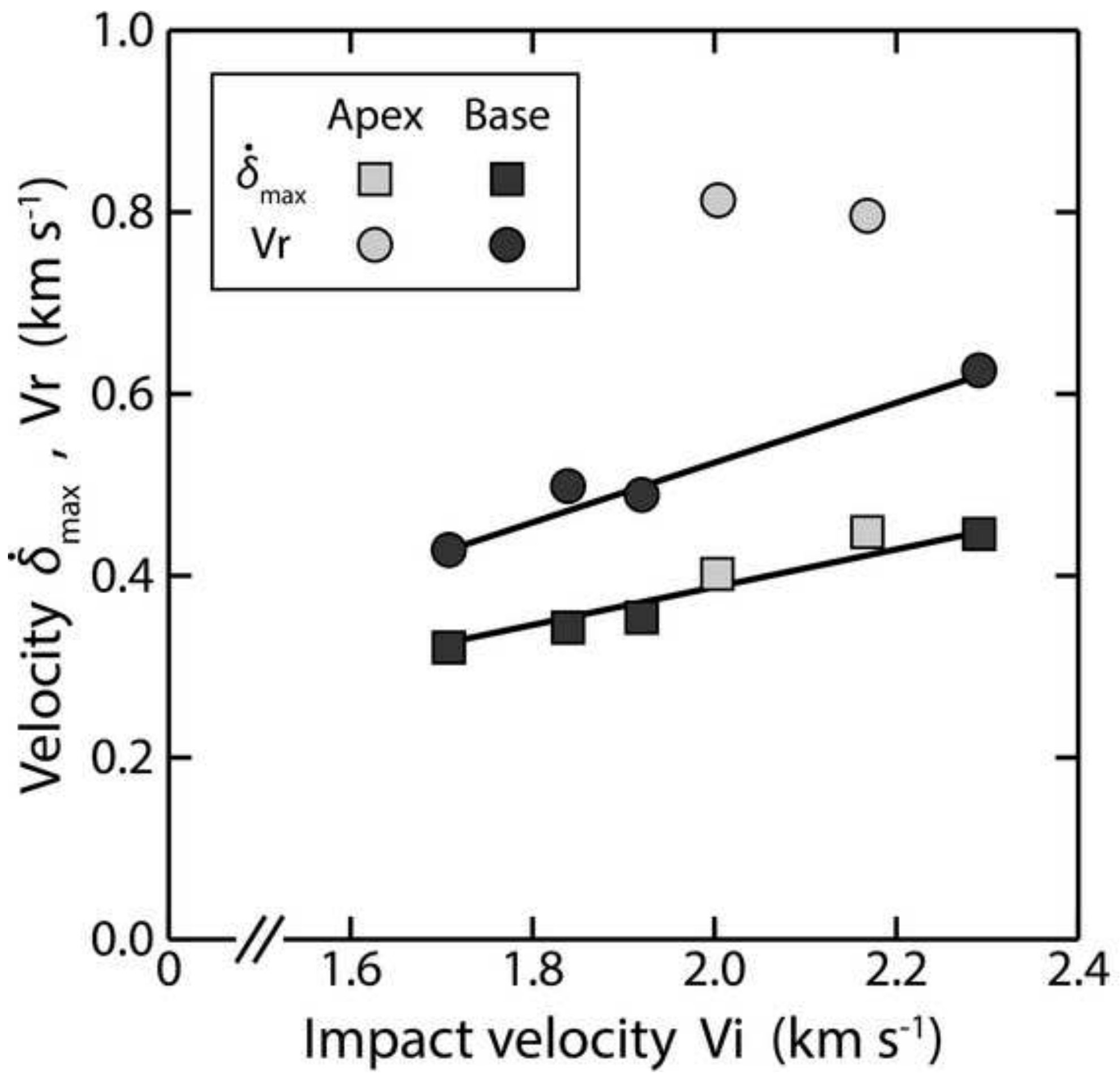




\begin{tabular}{|c|c|c|}
\hline $\mathrm{t}=-3 \mu \mathrm{s}$ & $.5 x+5$. & Al rearf \\
\hline & 1 & \\
\hline Hear- & 1 & \\
\hline adjacent & $1=$ & - Rear. \\
\hline Qude & $65^{2}$ & center \\
\hline & 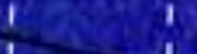 & node \\
\hline Transverse & $\frac{1}{1}-2 x$ & \\
\hline profile & 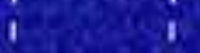 & \\
\hline & 1 & \\
\hline & I $-2=1$ & \\
\hline & $1=0 \quad 1$ & $Y$ \\
\hline$=1$ & 1 $y-3=1$ & \\
\hline
\end{tabular}
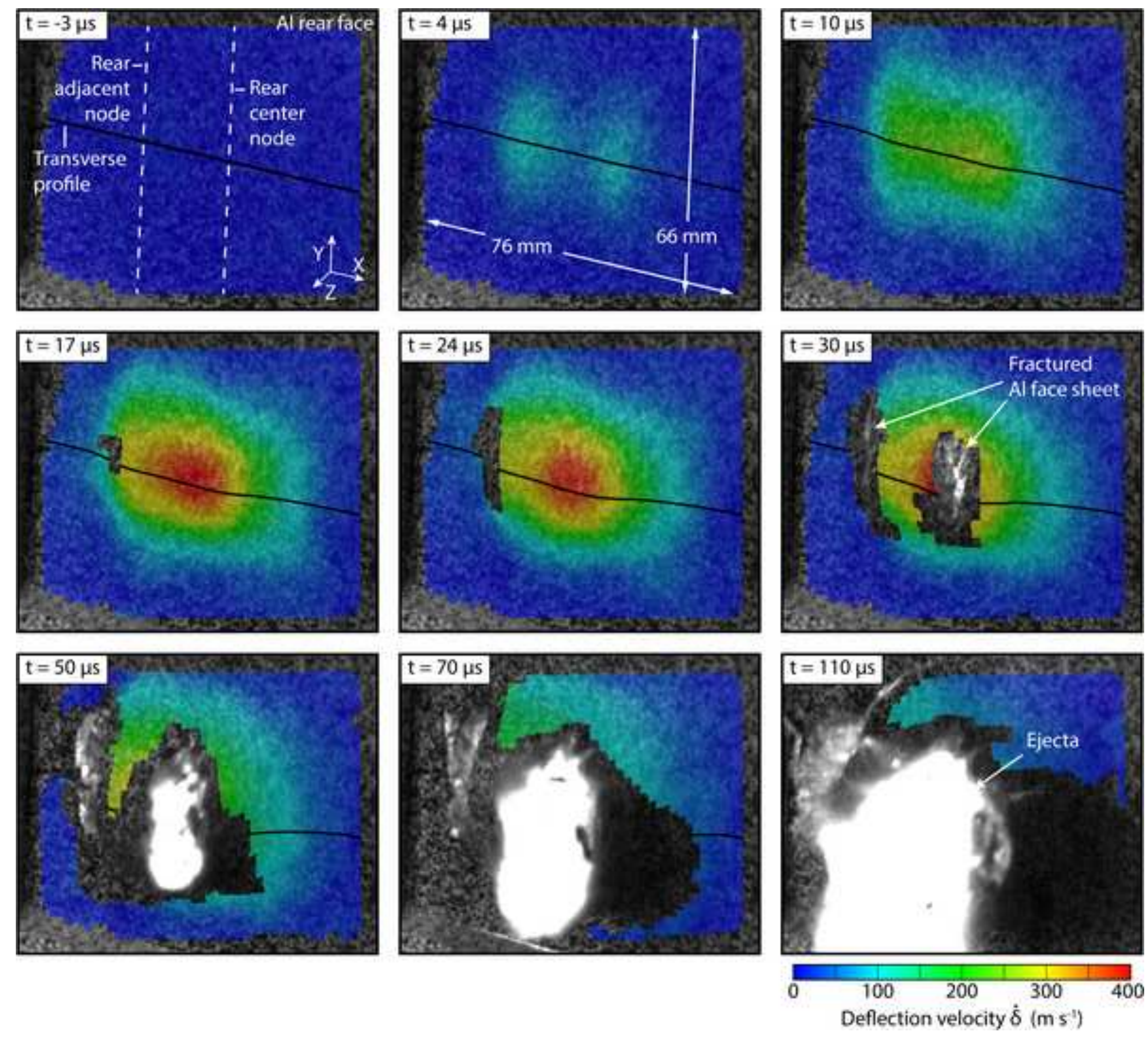


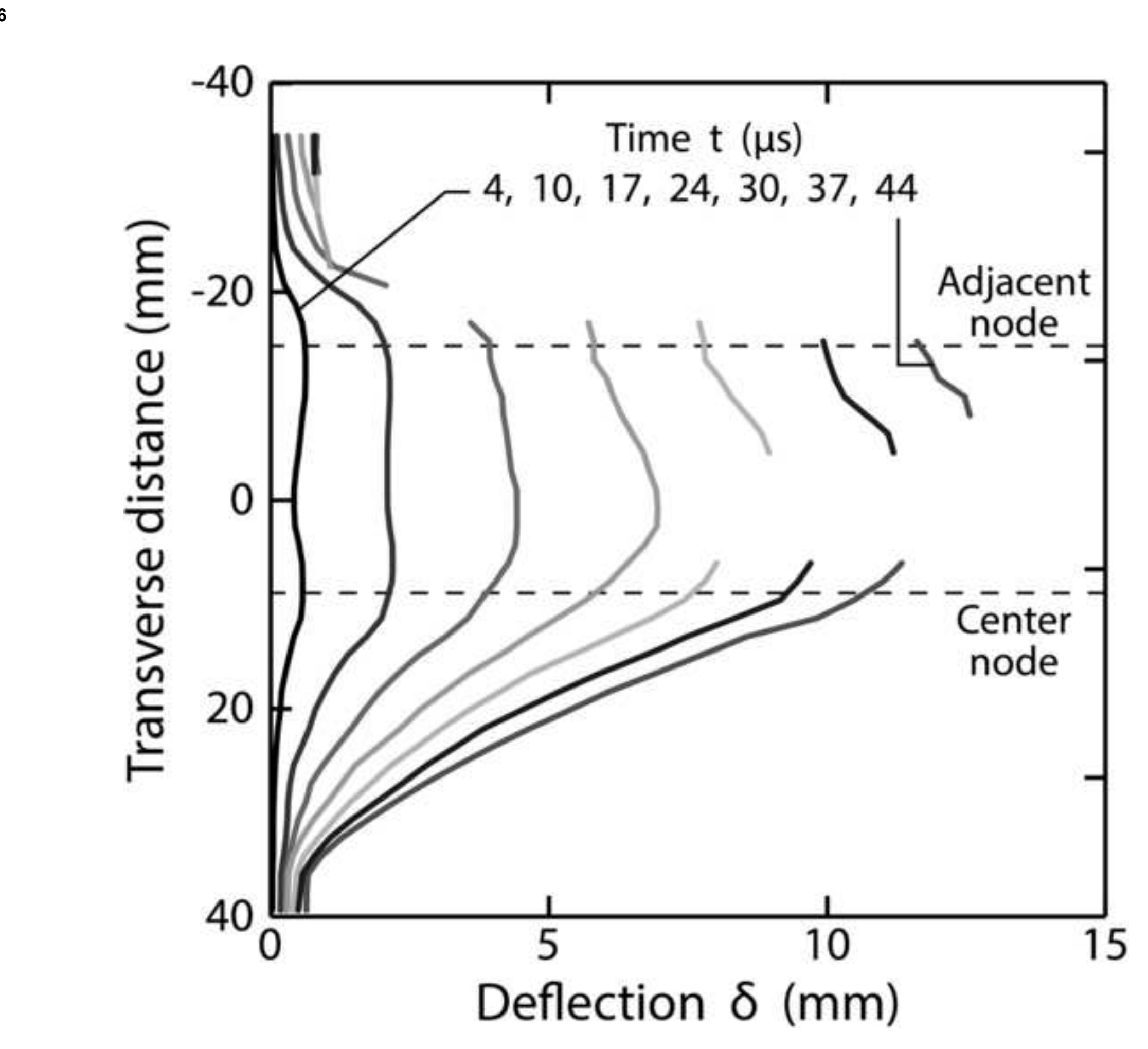


(a) Prism base impact - inital laminate loading

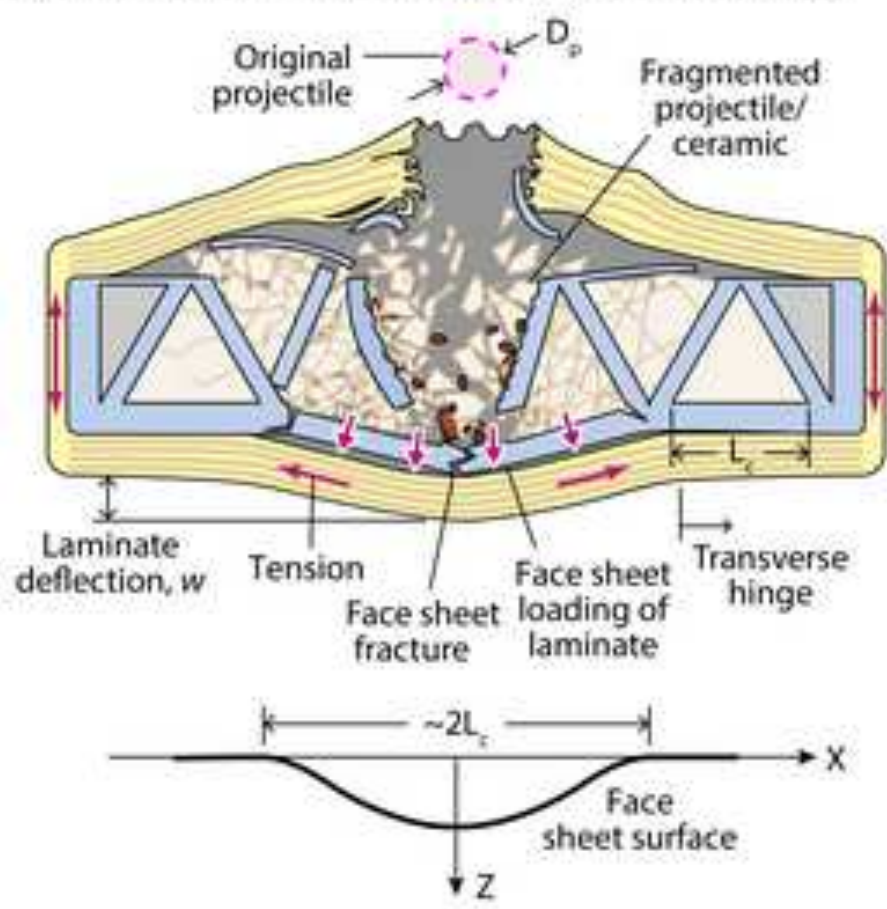

(c) Prism apex impact

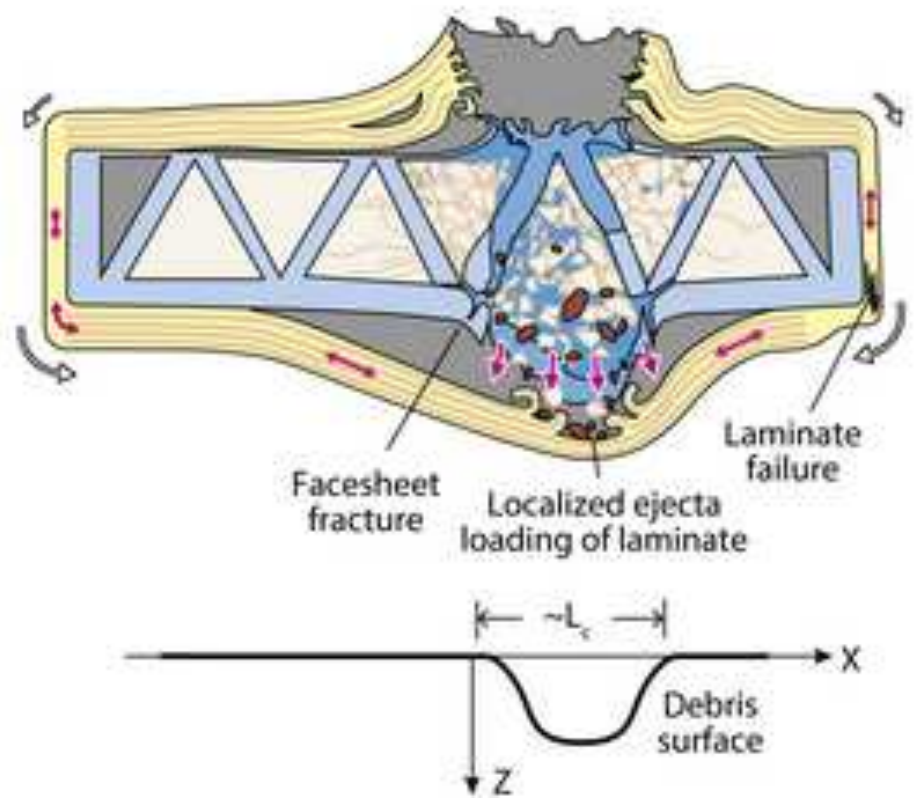

(b) Prism base impact - subsequent laminate loading

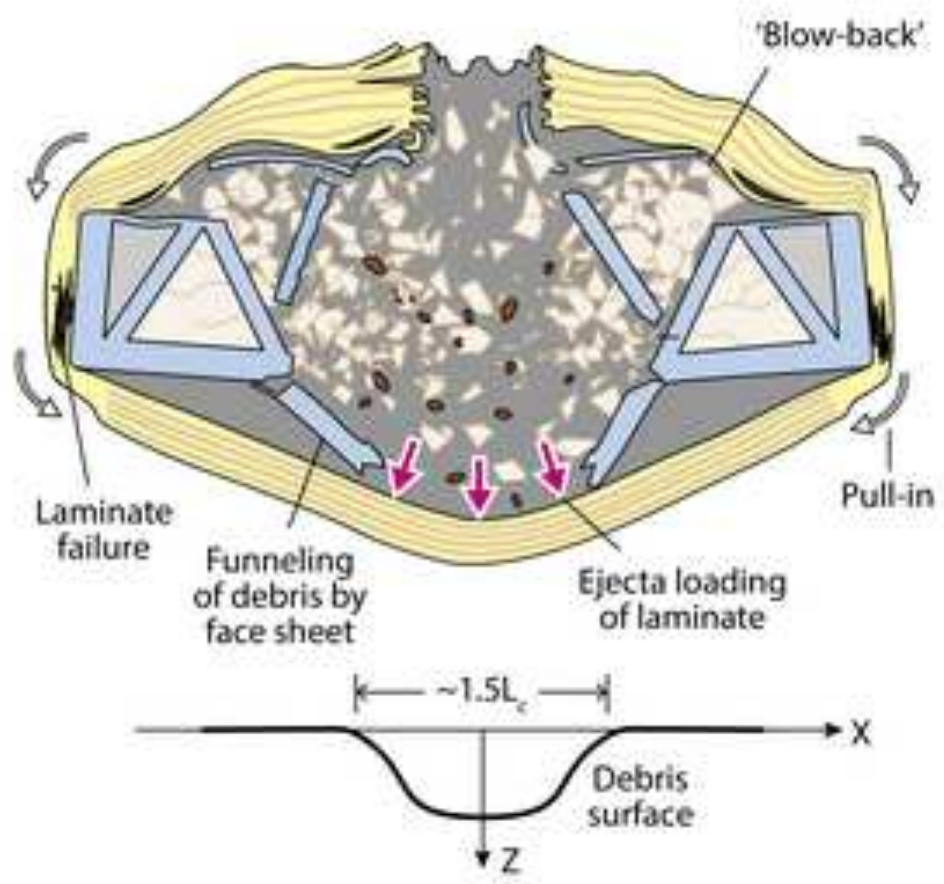

(d) Proposed deflection history

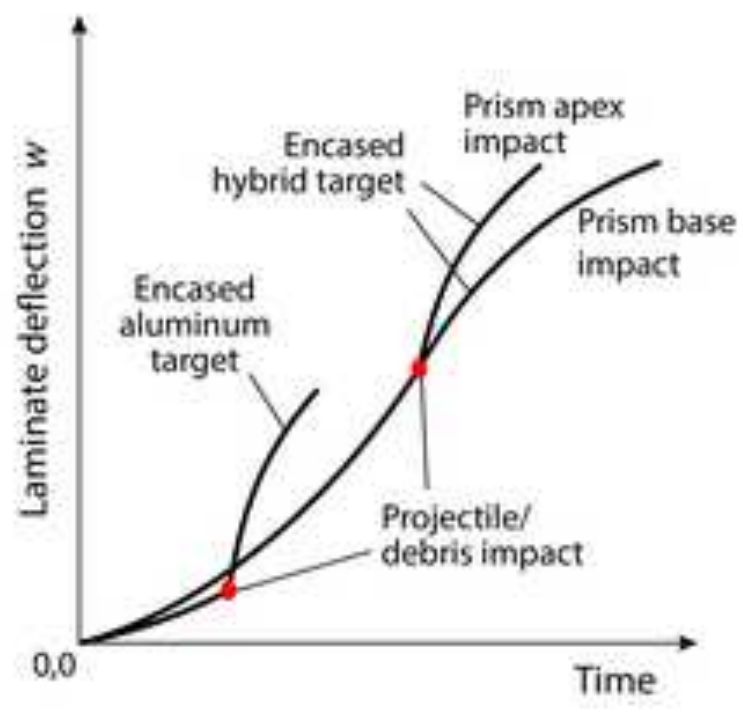

